\title{
Research on the Estimation Method of the Stiffness Degeneration Index of Reinforced Concrete Members
}

\author{
Yukui Wang $\mathbb{D}^{1,2}$ Zhefeng Liu $\mathbb{D}^{1,}{ }^{1,2}$ Weijun Yang, ${ }^{1}$ Jian Wang $\mathbb{D}^{1},{ }^{1}$ and Xiao Zheng $\mathbb{D}^{1}$ \\ ${ }^{1}$ College of Civil Engineering, Changsha University of Science \& Technology, Changsha 410004, China \\ ${ }^{2}$ Key Laboratory of Bridge Engineering Safety Control of China Ministry of Education, \\ Changsha University of Science \& Technology, Changsha, China \\ Correspondence should be addressed to Zhefeng Liu; 1zf0072006@163.com
}

Received 23 October 2019; Revised 20 January 2020; Accepted 22 January 2020; Published 29 February 2020

Academic Editor: Rafael J. Bergillos

Copyright (c) 2020 Yukui Wang et al. This is an open access article distributed under the Creative Commons Attribution License, which permits unrestricted use, distribution, and reproduction in any medium, provided the original work is properly cited.

Based on variable amplitude displacement cycle tests of 24 reinforced concrete members with different reinforcement conditions, the stiffness degradation index was proposed to describe the damage. The relationship between the stiffness degradation index, the displacement history, and the cumulative energy dissipation was studied; on this basis, an estimation method for the stiffness degradation index was proposed. By comparing the experimental values and estimated values of the stiffness degradation index, the proposed method provides promising prediction reliability and accuracy. The stiffness degradation index has an effective relationship with the structural design parameters. Based on the stiffness degradation index, the reinforced concrete members can be divided into five performance levels: no damage $\left(D_{\mathrm{K}, k}<0\right)$, mild damage $\left(0<D_{\mathrm{K}, k} \leq 0.3\right)$, moderate damage $\left(0.3<D_{\mathrm{K}, k} \leq 0.7\right)$, severe damage $\left(0.7<D_{\mathrm{K}, k} \leq 0.9\right)$, and destruction $\left(0.9<D_{\mathrm{K}, k} \leq 1\right)$, which can provide a good reference for the seismic design of reinforced concrete members. The increase in the transverse reinforcement ratio can significantly reduce the stiffness damage, and the effect is more obvious under the conditions of small ductility. Under the same conditions, the smaller the ductility condition is, the smaller the stiffness damage of the reinforced concrete members will be. Therefore, the control of the ductility condition and the increase in the transverse reinforcement ratio are stable and effective methods for controlling the stiffness damage of reinforced concrete members.

\section{Introduction}

In performance-based design methods, the determination of the structural performance levels is based on the damage index [1-3]. Since the deformation-based damage index is not convenient for considering damage accumulation, it is the development direction of the research on the damage index to consider the deformation and cumulative energy dissipation [4-7].

In 1986, Park and Ang [5] proposed the Park-Ang damage index by linearly combining the deformation damage term with the energy damage term. The damage index has an effective relationship with the structural design parameters (such as the ductility, yielding load, and reinforcement), which can provide a good reference for seismic design [6]. Therefore, an increasing number of applications have been obtained [7]. However, the simplified calculation method for the damage index cannot fully reflect the damage mechanism. On the one hand, the influence of the difference displacement path is not considered in the damage index, while the deformation capacity and energy dissipation capacity of the structure are related to the displacement history $[8,9]$. On the other hand, to maintain the linear expression of the damage index, the nonlinear relationship between the deformation damage term and the energy damage term is completely borne by the influence of the factor beta, which results in a large dispersion of the statistical results of the beta value. To accommodate for these shortcomings, scholars have performed many revisions on the determination of on the damage index $[10,11]$, which are of great significance for perfecting the damage index. However, these revisions do 
not touch on the influence of the variable amplitude displacement history on the damage development, which causes the verification of the revised damage index to lack sufficient theoretical support.

Another type of damage index describes the damage according to the change in the structural characteristics before and after damage, such as the stiffness [12-14], period [15], and deformation energy [16]. These damage indexes do not directly contain the deformation damage term and energy dissipation term but reflect the results caused by two kinds of damage terms. Since this type of damage index corresponds to concrete physical indicators, the physical meaning of the damage index is clear, and the verification is more convenient. However, this kind of damage index is not directly linked to the design parameters of the structure, so it is not convenient for guiding the performance design of the structure.

In this paper, based on the variable amplitude displacement cycle tests of 24 reinforced concrete members [17], the stiffness degradation index was proposed to describe the damage. The relationship between the stiffness degradation index and the energy dissipation capacity, displacement path, and structural design parameters was studied. On this basis, an estimation method of the stiffness degradation index was proposed, which is intended to provide a reference for seismic design and damage assessment of reinforced concrete members in the future.

\section{Experiments}

Twenty-four specimens in the companion paper [17] were selected for this paper. As shown in Figure 1, the dimensions and details of the 24 specimens were identical except for the longitudinal reinforcement ratio in the test section and the transverse reinforcement ratio at the plastic hinge region. The length of the test section was $1500 \mathrm{~mm}$, and the crosssection size was $250 \mathrm{~mm} \times 350 \mathrm{~mm}$.

The properties and imposed displacement patterns of the 24 specimens are summarized in Table 1 . The yield loads and the yield displacements of the 24 specimens were calculated from the skeletal curves according to the equal energy criterion. Specimens R1 to R18 were divided into six groups according to reinforcement type, and three specimens in each group had the same reinforcement type.

Stable variable (SV) displacement patterns were imposed on specimens R1 to R18. An SV displacement pattern was composed of several constant-amplitude cycle (CC) stages. As shown in Figure 2, the SV displacement pattern was composed of four CC stages, and the displacement amplitudes of the four CC stages were $20 \mathrm{~mm}, 40 \mathrm{~mm}, 60 \mathrm{~mm}$, and $40 \mathrm{~mm}$. The first stage of the CC was defined as the initial half-cycle sequence (IHS). For the subsequent stages of the CC, when the displacement amplitude was smaller than the maximum historical displacement amplitude, the CC stage was defined as the smaller subsequent half-cycle sequence
(SSHS); when the displacement amplitude was larger than the maximum historical displacement amplitude, the CC stage was defined as the larger subsequent half-cycle sequence (LSHS). Six SV displacement patterns were designed in the test.

The random variable (RV) displacement patterns were imposed on specimens R19 to R24, and the displacement patterns RV1 and RV2 were imposed on test specimens R19 to R21 and R22 to R24, respectively. The RV displacement patterns imposed on the test specimens are shown in Figure 3. Details of the test can be found in the companion paper [17].

\section{The Stiffness Degradation Index of the Reinforced Concrete Members}

3.1. The Stiffness Degradation Index under the SV Displacement Patterns. The hysteresis path between two consecutive zero-forces is defined as a half-cycle. As shown in Figure 4, the abscissa axis is the displacement amplitude, the ordinate axis is the force, and one hysteresis loop is divided into upper and lower half-cycles by the abscissa axis. $u_{k}$ is the displacement amplitude of the $k$-th half-cycle. The slope of the red line $K_{k}$ is defined as the initial loading stiffness of the $k$-th half-cycle.

The stiffness degradation index of the reinforced concrete members is defined as

$$
D_{\mathrm{K}, k}=1-\frac{K_{k}}{V_{\mathrm{y}} / u_{\mathrm{y}}},
$$

When the initial stiffness $K_{k}$ is larger than $V_{\mathrm{y}} / u_{\mathrm{y}}$, the value of $D_{\mathrm{K}, k}$ is taken as 0 . The initial loading stiffness of each half-cycle of the 24 specimens was extracted, and the stiffness degradation index of each half-cycle was calculated according to equation (1).

The $D_{\mathrm{K}, k^{-}} k$ relations of specimens $\mathrm{R} 1$ to $\mathrm{R} 24$ are shown in Figure 5. It can be seen that (1) whether the displacement pattern is an $\mathrm{SV}$ or $\mathrm{RV}$, the value of $D_{\mathrm{K}, k}$ monotonically increased from 0 to 1 ; (2) the difference in the displacement patterns has a significant influence on the development of $D_{\mathrm{K}, k}$. For the three specimens of the same group, when the displacement amplitude increases gradually from small to large (SV1 pattern), the development of $D_{\mathrm{K}, k}$ is the slowest; when the displacement amplitude decreases gradually from large to small (SV3 pattern), the development of $D_{\mathrm{K}, k}$ is the fastest. (3) The increase in the reinforcement ratio can slow down the development of $D_{K, k}$, which is more effective under the SV1 displacement pattern (such as specimens R1, R4, and R7).

To study the relationship between $D_{\mathrm{K}, k}$, the displacement history (deformation damage term), and the cumulative energy dissipation (cumulative damage term) and to obtain a simplified estimation method for $D_{\mathrm{K}, k}$, the normalized effective amplitude $\mu_{k}$ and the normalized cumulative energy dissipation $n_{k}$ at the $k$ half-cycle are defined as [17] 


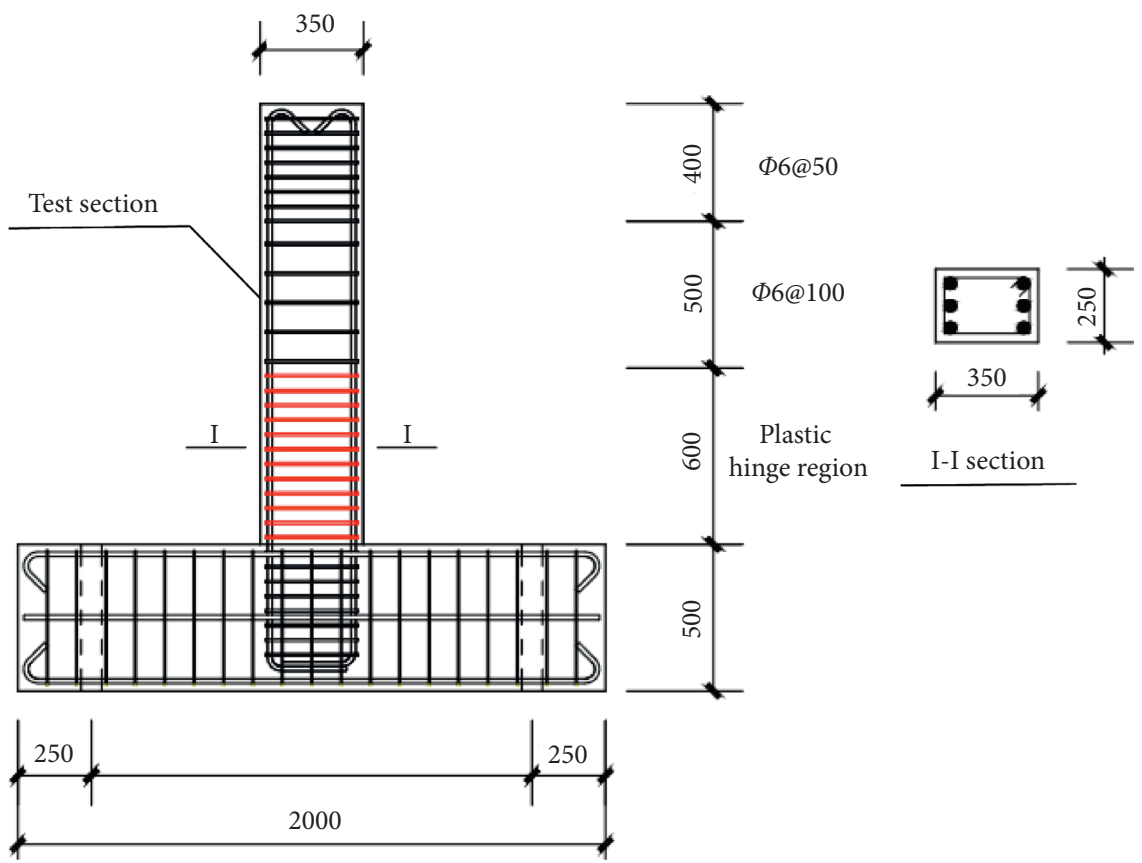

Figure 1: Test specimen (dimensions in $\mathrm{mm}$ ).

TABLE 1: The properties and imposed displacement patterns of 24 specimens [17].

\begin{tabular}{|c|c|c|c|c|c|c|c|}
\hline \multicolumn{2}{|c|}{ Specimen } & \multirow{2}{*}{$V_{\mathrm{y}}(\mathrm{kN})$} & \multirow{2}{*}{$u_{\mathrm{y}}(\mathrm{mm})$} & \multirow{2}{*}{$\rho_{\mathrm{w}}(\%)$} & \multirow{2}{*}{$\rho(\%)$} & \multirow{2}{*}{ Displacement pattern } & \multirow{2}{*}{ Displacement amplitude of CC stage } \\
\hline Group & No. & & & & & & \\
\hline \multirow{3}{*}{1} & $\mathrm{R} 1$ & 67.60 & 12.97 & \multirow{3}{*}{0.226} & \multirow{3}{*}{0.766} & SV1 & $20 \mathrm{~mm}, 40 \mathrm{~mm}$ and $60 \mathrm{~mm}$ \\
\hline & $\mathrm{R} 2$ & 67.60 & 12.97 & & & SV2 & $40 \mathrm{~mm}, 20 \mathrm{~mm}$ and $60 \mathrm{~mm}$ \\
\hline & R3 & 67.60 & 12.97 & & & SV3 & $60 \mathrm{~mm}, 40 \mathrm{~mm}$ and $20 \mathrm{~mm}$ \\
\hline \multirow{3}{*}{2} & $\mathrm{R} 4$ & 67.60 & 12.97 & \multirow{3}{*}{0.402} & \multirow{3}{*}{0.766} & SV1 & $20 \mathrm{~mm}, 40 \mathrm{~mm}$ and $60 \mathrm{~mm}$ \\
\hline & R5 & 67.60 & 12.97 & & & SV2 & $40 \mathrm{~mm}, 20 \mathrm{~mm}$ and $60 \mathrm{~mm}$ \\
\hline & R6 & 67.60 & 12.97 & & & SV3 & $60 \mathrm{~mm}, 40 \mathrm{~mm}$ and $20 \mathrm{~mm}$ \\
\hline \multirow{3}{*}{3} & $\mathrm{R} 7$ & 67.60 & 12.97 & \multirow{3}{*}{0.804} & \multirow{3}{*}{0.766} & SV1 & $20 \mathrm{~mm}, 40 \mathrm{~mm}$ and $60 \mathrm{~mm}$ \\
\hline & $\mathrm{R} 8$ & 67.60 & 12.97 & & & SV2 & $40 \mathrm{~mm}, 20 \mathrm{~mm}$ and $60 \mathrm{~mm}$ \\
\hline & R9 & 67.60 & 12.97 & & & SV3 & $60 \mathrm{~mm}, 40 \mathrm{~mm}$ and $20 \mathrm{~mm}$ \\
\hline \multirow{3}{*}{4} & $\mathrm{R} 10$ & 51.50 & 11.70 & \multirow{3}{*}{0.402} & \multirow{3}{*}{0.587} & SV4 & $20 \mathrm{~mm}, 40 \mathrm{~mm}, 60 \mathrm{~mm}$ and $40 \mathrm{~mm}$ \\
\hline & $\mathrm{R} 11$ & 51.50 & 11.70 & & & SV5 & $40 \mathrm{~mm}, 20 \mathrm{~mm}, 60 \mathrm{~mm}$ and $40 \mathrm{~mm}$ \\
\hline & $\mathrm{R} 12$ & 51.50 & 11.70 & & & SV6 & $60 \mathrm{~mm}, 40 \mathrm{~mm}, 20 \mathrm{~mm}$ and $40 \mathrm{~mm}$ \\
\hline \multirow{3}{*}{5} & $\mathrm{R} 13$ & 80.11 & 14.39 & \multirow{3}{*}{0.402} & \multirow{3}{*}{0.971} & SV4 & $20 \mathrm{~mm}, 40 \mathrm{~mm}, 60 \mathrm{~mm}$ and $40 \mathrm{~mm}$ \\
\hline & $\mathrm{R} 14$ & 80.11 & 14.39 & & & SV5 & $40 \mathrm{~mm}, 20 \mathrm{~mm}, 60 \mathrm{~mm}$ and $40 \mathrm{~mm}$ \\
\hline & $\mathrm{R} 15$ & 80.11 & 14.39 & & & SV6 & $60 \mathrm{~mm}, 40 \mathrm{~mm}, 20 \mathrm{~mm}$ and $40 \mathrm{~mm}$ \\
\hline \multirow{3}{*}{6} & $\mathrm{R} 16$ & 89.02 & 16.66 & \multirow{3}{*}{0.402} & \multirow{3}{*}{1.198} & SV4 & $20 \mathrm{~mm}, 40 \mathrm{~mm}, 60 \mathrm{~mm}$ and $40 \mathrm{~mm}$ \\
\hline & $\mathrm{R} 17$ & 89.02 & 16.66 & & & SV5 & $40 \mathrm{~mm}, 20 \mathrm{~mm}, 60 \mathrm{~mm}$ and $40 \mathrm{~mm}$ \\
\hline & $\mathrm{R} 18$ & 89.02 & 16.66 & & & SV6 & $60 \mathrm{~mm}, 40 \mathrm{~mm}, 20 \mathrm{~mm}$ and $40 \mathrm{~mm}$ \\
\hline \multirow{3}{*}{7} & R19 & 67.60 & 12.97 & 0.226 & 0.766 & RV1 & - \\
\hline & $\mathrm{R} 20$ & 67.60 & 12.97 & 0.402 & 0.766 & RV1 & - \\
\hline & $\mathrm{R} 21$ & 89.02 & 16.66 & 0.402 & 1.198 & RV1 & - \\
\hline \multirow{3}{*}{8} & $\mathrm{R} 22$ & 89.02 & 16.66 & 0.804 & 1.198 & RV2 & - \\
\hline & $\mathrm{R} 23$ & 89.02 & 16.66 & 0.226 & 1.198 & RV2 & - \\
\hline & $\mathrm{R} 24$ & 51.50 & 11.70 & 0.226 & 0.587 & RV2 & - \\
\hline
\end{tabular}

Note. $V_{\mathrm{y}}$ is the yield load, $u_{\mathrm{y}}$ is the yield displacement, $\rho_{\mathrm{w}}$ is the transverse reinforcement ratio at the plastic hinge region, and $\rho$ is the longitudinal reinforcement ratio in the test section. 


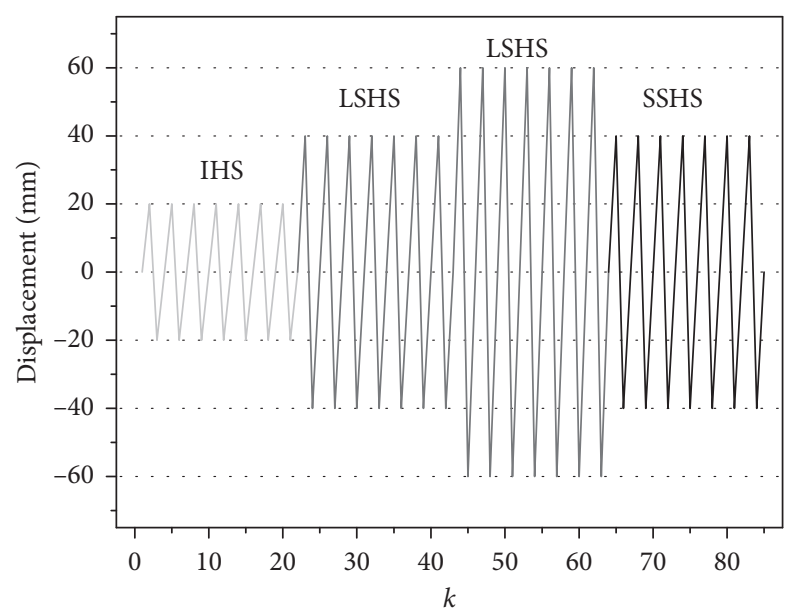

FIGURE 2: The SV displacement pattern, which was composed of four CC stages.

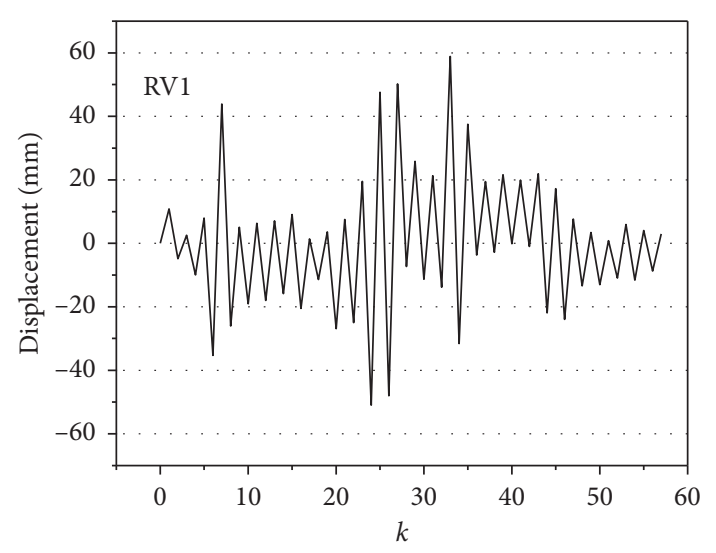

(a)

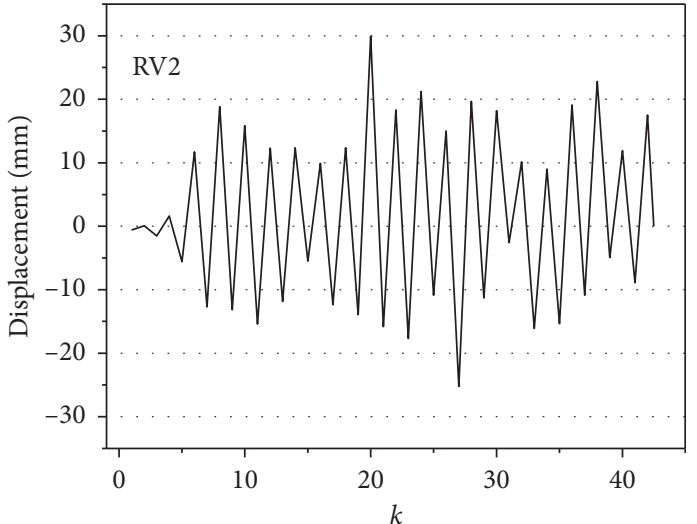

(b)

FIgUre 3: The RV displacement patterns imposed on the test specimens [17]: (a) RV1. (b) RV2.

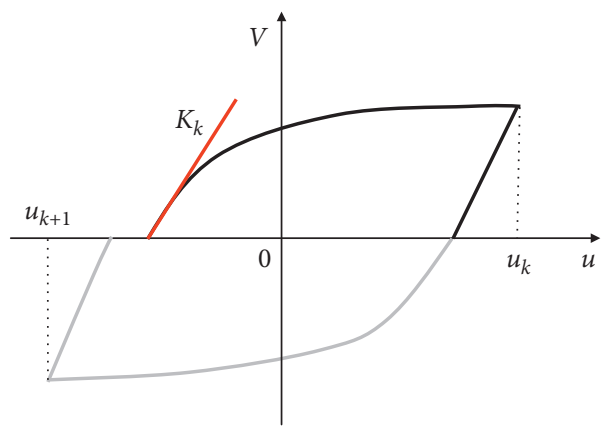

Figure 4: The initial loading stiffness of the $k$-th half-cycle.

$\mu_{k}= \begin{cases}\frac{\left(\left|\cdot \mathrm{u}_{k}\right|+\left|u_{k-1}\right|\right)}{2 u_{\mathrm{y}}}, & k>1, \\ \frac{\left|u_{k}\right|}{u_{\mathrm{y}}}, & k=1 .\end{cases}$

$n_{k}=\frac{\sum_{i=1}^{k-1} E_{\mathrm{H}, i}}{0.5 V_{\mathrm{y}} u_{\mathrm{y}}}$.
Here, $\sum_{i=1}^{k-1} E_{\mathrm{H}, i}$ is the sum of dissipated energy from the first to the $k$-1th half-cycle.

The $D_{\mathrm{K}, k}-n_{k}$ relations for specimens $\mathrm{R} 4$ to $\mathrm{R} 6, \mathrm{R} 7$ to $\mathrm{R} 9$, and R10 to R12 are shown in Figure 6. The different halfcycle sequences (HS) are represented by different symbols in Figure 6 . The number next to the symbol represents the value of $\mu_{k}$ of the HS. 


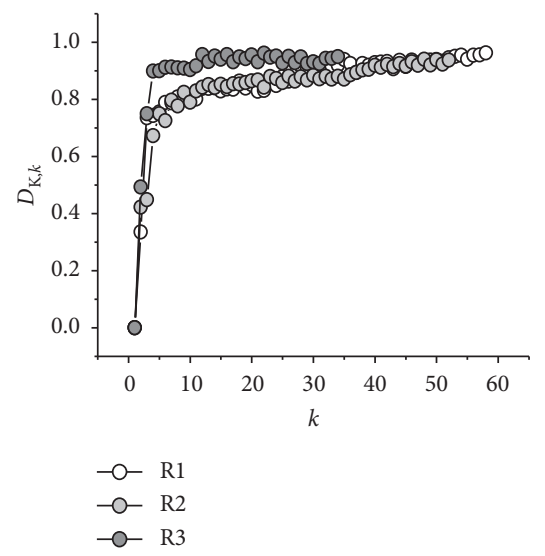

(a)

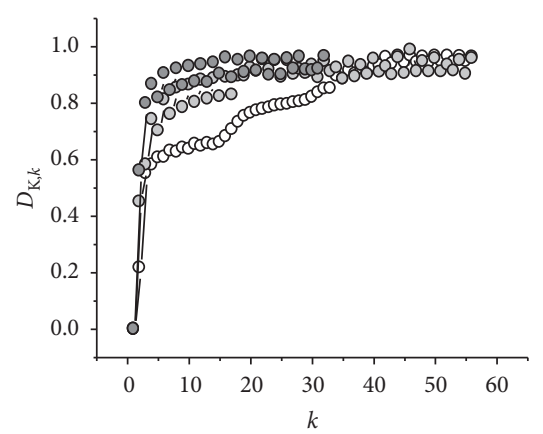

$-\mathrm{O}-\mathrm{R} 10$

-O- R11

-O- R12

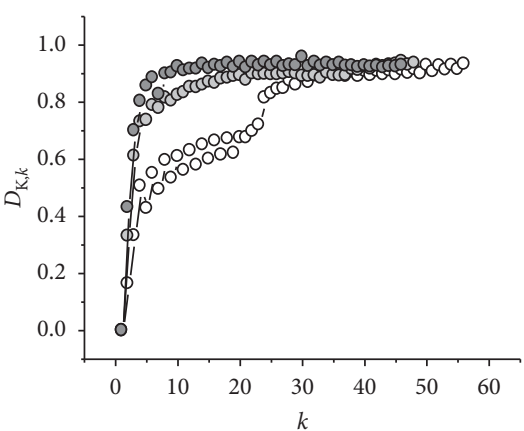

$-\mathrm{O}$ R4

-O- R5

-O R6

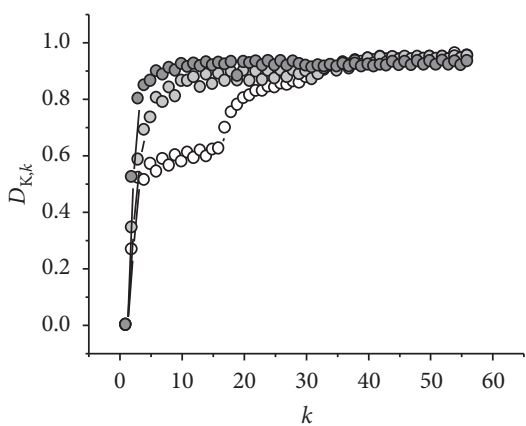

$-\mathrm{O}-\mathrm{R} 13$
$-\mathrm{O}-\mathrm{R} 14$

-O- R15

(d)

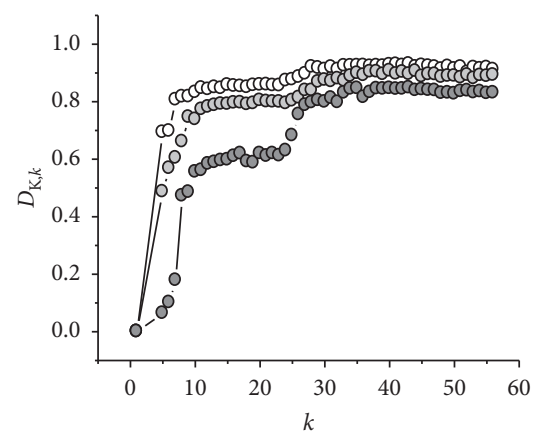

$-\mathrm{O}-\mathrm{R} 19$
$-\mathrm{O}-\mathrm{R} 20$
$-\mathrm{O}-\mathrm{R} 21$ (b)

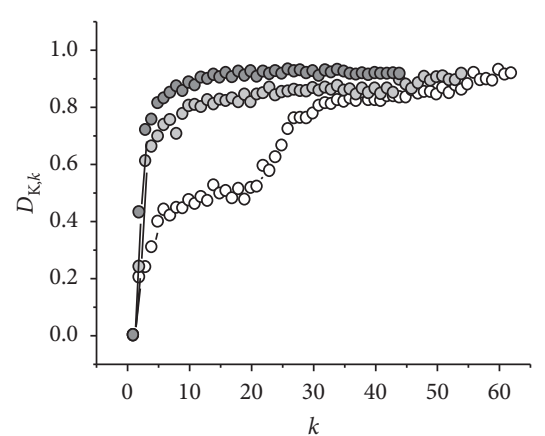

$-\mathrm{O}$ R7

$\rightarrow$ R8

-O- R9

(c)

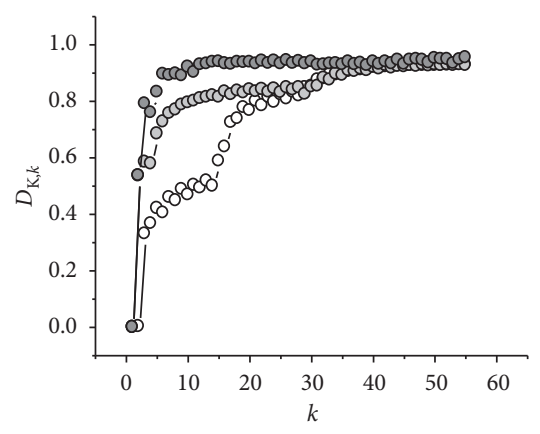

$-\mathrm{O}-\mathrm{R} 16$

-O- R17

-O R18

(e)

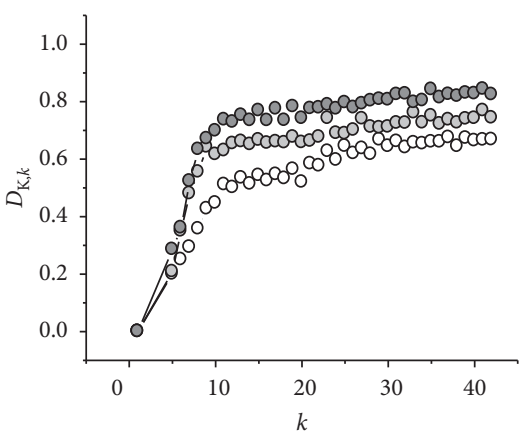

-O- R22
-O- R23
- - R24

(h)

FIGURE 5: $D_{\mathrm{K}, k}$-k relations of specimens R1 to R24. (a) Group 1. (b) Group 2. (c) Group 3. (d) Group 4. (e) Group 5. (f) Group 6. (g) Group 7. (h) Group 8.

3.1.1. $D_{\mathrm{K}, k^{-}} n_{k}$ Relations for the Initial Half-Cycle Sequence (IHS). Figure 6 shows that the $D_{\mathrm{K}, k}-n_{k}$ relations for the IHS increase monotonically from 0 to 1 , but the slope of the $D_{\mathrm{K}, k}-n_{k}$ relations for the IHS gradually decreases with increasing $n_{k}$. According to these characteristics, a damage model of the stiffness degradation index for the IHS is proposed:

$$
D_{\mathrm{K}, k}=\alpha\left(1-e^{-\beta n_{k}}\right) .
$$

As shown in Figure 7, parameter $\alpha$ is the peak value of $D_{\mathrm{K}, k}$ when the stiffness deterioration tends to stop, the value of parameter $\alpha$ varies from 0 to 1 , and the larger the value of parameter $\alpha$ is, the more severe the stiffness degradation is. Parameter $\beta$ reflects the energy dissipation requirements of the stiffness degradation, and the value of the parameter $\beta$ varies from 0 to $\infty$. The larger the value of the parameter $\beta$ is, the steeper the $D_{\mathrm{K}, k}-n_{k}$ relation is, which means that less energy is dissipated when the stiffness deterioration tends to stop. 


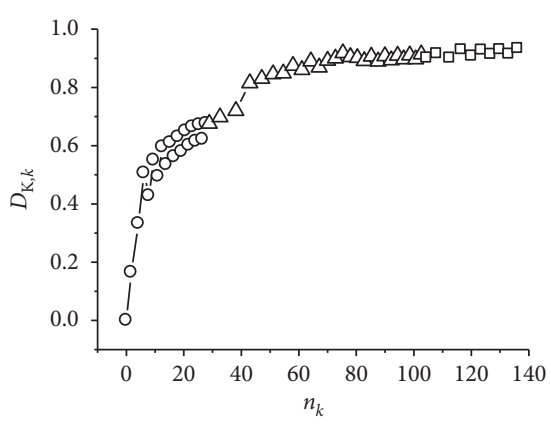

R4

- 1.54 -IHS

$\neg$ 3.08-LSHS

$\rightarrow$ 4.62-LSHS

(a)

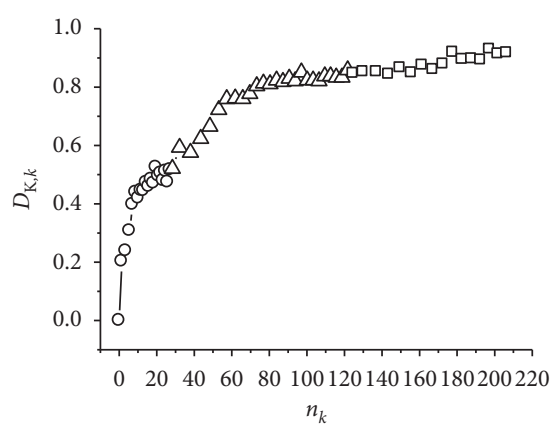

R7

-0 1.54-IHS

$\triangle$ 3.08-LSHS

$\rightarrow$ 4.62-LSHS

(d)

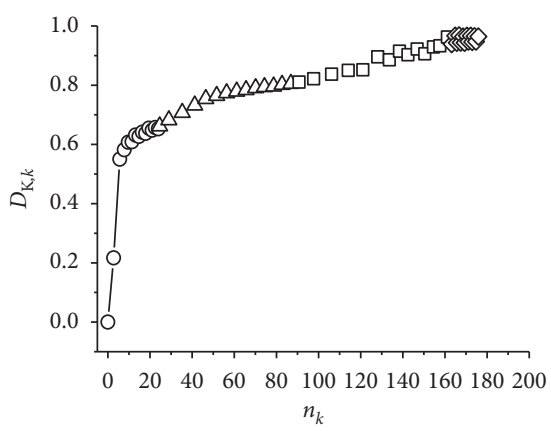

$$
\begin{array}{llll}
\text { R10 } & & & \\
-0 & \text { 1.81-IHS } & - & \text { 5.42-LSHS } \\
- & \text { 3.61-LSHS } & \sim & \text { 3.61-SSHS }
\end{array}
$$

(g)

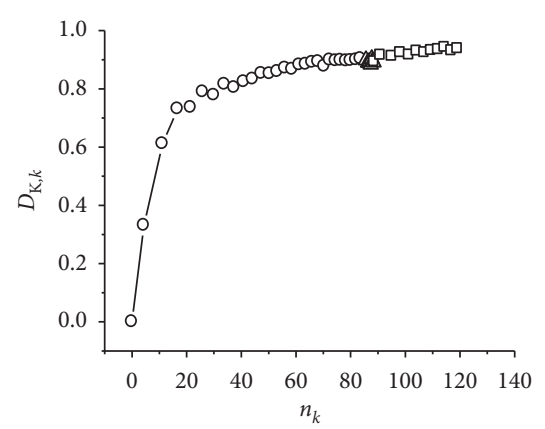

R5

-O 3.08-IHS

$\triangle$ 1.54-SSHS

$\rightarrow$ 4.62-LSHS

(b)

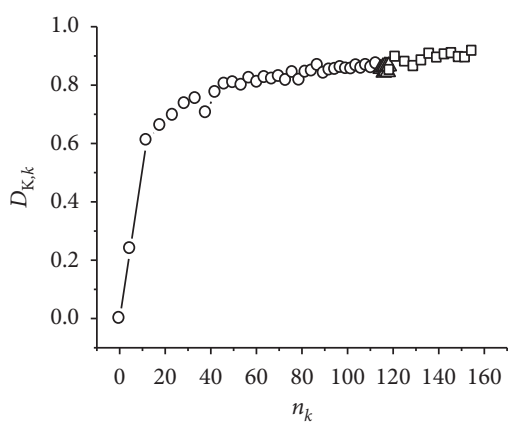

R8

-0 3.08-IHS

$\triangle \quad$ 1.54-SSHS

$\rightarrow$ 4.62-LSHS

(e)

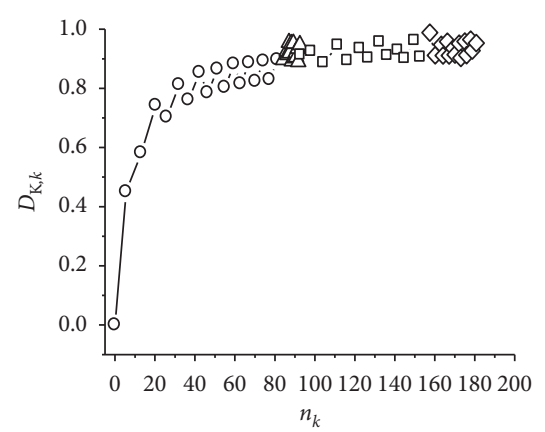

R11

- - 3.61-IHS $\square$ 5.42-LSHS

$\checkmark$ 1.81-SSHS $\prec$ 3.61-SSHS

(h)

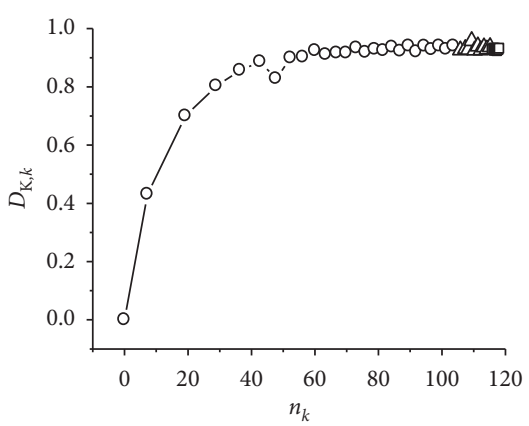

R6

-

$\triangle$ 3.08-SSHS

$\rightarrow$ 1.54-SSHS

(c)

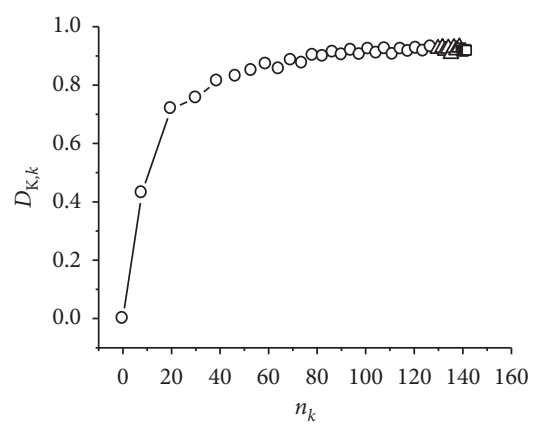

R9

- -4.62 -IHS

$\triangle$ 3.08-SSHS

$\neg$ 1.54-SSHS

(f)

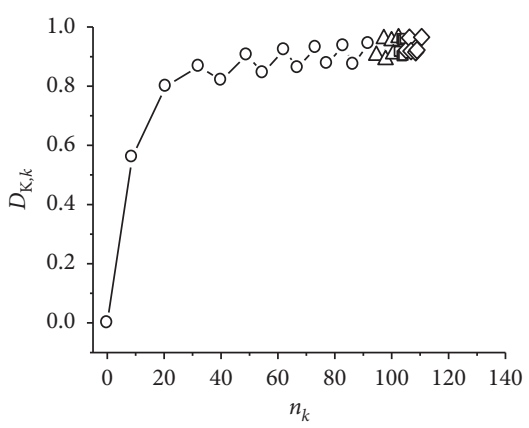

$\begin{array}{llll}\text { R12 } & & & \\ \multimap & \text { 5.42-IHS } & - & \text { 1.81-SSHS } \\ \smile & \text { 3.61-SSHS } & \checkmark & \text { 3.61-SSHS }\end{array}$

(i)

Figure 6: $D_{\mathrm{K}, k}-n_{k}$ relations for specimens R4 to R6, R7 to R9, and R10 to R12.

According to equation (4), the $D_{\mathrm{K}, k}-n_{k}$ relations for the IHS are fitted by a nonlinear regression analysis procedure, and the values of parameter $\alpha$ and parameter $\beta$ are obtained. The values of parameter $\alpha$ and parameter $\beta$ for specimens R1 to $\mathrm{R} 18$ are given in Table 2.

The relationship between $\mu_{k}$ and parameter $\alpha$ is shown in Figure 8. It can be seen that the value of parameter $\alpha$ increased with increasing $\mu_{k}$. Figures $8(\mathrm{a})$ and 8(b) show the influence of $\rho$ and $\rho_{\mathrm{w}}$ on the $\alpha-\mu_{k}$ relations, respectively. The influence of $\rho$ on the $\alpha-\mu_{k}$ relations is not clear, but the difference of $\rho_{\mathrm{w}}$ causes the $\alpha-\mu_{k}$ relations to be obviously stratified, and the increase in $\rho_{\mathrm{w}}$ leads to the decrease of parameter $\alpha$. Based on the correlation of parameter $\alpha$ with $\rho_{\mathrm{w}}$ and $\mu_{k}$, equation (5) is obtained by nonlinear curve fitting of the data points in Figure 8(b).

$$
\alpha=0.95\left(1-e^{-\mu_{k}\left(0.68+11.35 e^{-14.24 \rho_{\mathrm{w}}}\right)}\right) .
$$




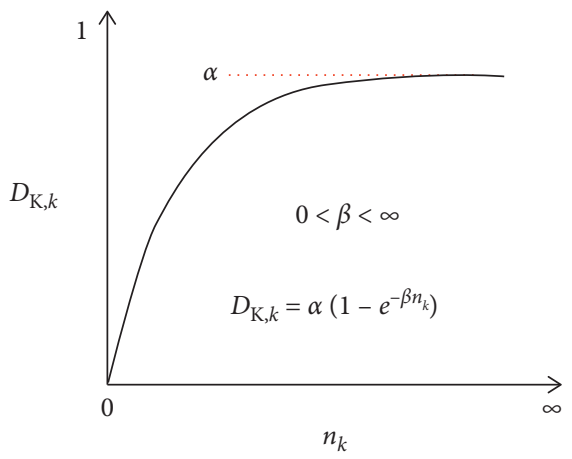

FIgURE 7: Damage model of the stiffness degradation index for the IHS.

TABLE 2: The values of parameter $\alpha$ and parameter $\beta$ for specimens R1 to R18.

\begin{tabular}{lcc}
\hline No. & $\alpha$ & $\beta$ \\
\hline R1 & 0.833 & 0.486 \\
R2 & 0.910 & 0.148 \\
R3 & 0.932 & 0.093 \\
R4 & 0.641 & 0.174 \\
R5 & 0.876 & 0.094 \\
R6 & 0.924 & 0.074 \\
R7 & 0.620 & 0.160 \\
R8 & 0.838 & 0.080 \\
R9 & 0.902 & 0.071 \\
R10 & 0.660 & 0.234 \\
R11 & 0.842 & 0.099 \\
R12 & 0.894 & 0.108 \\
R13 & 0.596 & 0.608 \\
R14 & 0.864 & 0.121 \\
R15 & 0.910 & 0.126 \\
R16 & 0.551 & 0.263 \\
R17 & 0.768 & 0.153 \\
R18 & 0.901 & \\
\hline
\end{tabular}

As shown in Figure 9, the relationship between $\mu_{k}$ and parameter $\beta$ presents a decreasing function. Figures 9(a) and 9(b) show the influence of $\rho$ and $\rho_{\mathrm{w}}$ on the $\beta-\mu_{k}$ relations, respectively. Similar to Figures $8(\mathrm{a})$ and $8(\mathrm{~b})$, only $\rho_{\mathrm{w}}$ has a regular influence on the development of the $\beta-\mu_{k}$ relations, and the increase in $\rho_{\mathrm{w}}$ leads to the decrease in parameter $\beta$. Based on the correlation of the parameter $\beta$ with $\rho_{\mathrm{w}}$ and $\mu_{k}$, equation (6) is obtained by nonlinear curve fitting of the data points in Figure 9(b).

$$
\beta=\frac{0.31 \rho_{\mathrm{w}}^{-1.56}}{\left(1+\mu_{k}\right)^{1.04 \rho_{\mathrm{w}}^{-0.45}}} .
$$

3.1.2. $D_{\mathrm{K}, k}-n_{k}$ Relations of the Subsequent Half-Cycle Sequence (SHS). As shown in Figure 6, the $D_{\mathrm{K}, k}-n_{k}$ relation of the SSHS continues the trajectory of the previous CC stage. For the LSHS, the $D_{\mathrm{K}, k}-n_{k}$ relation increases rapidly on the basis of the previous CC stage and then tends to stabilize. The shape of the $D_{\mathrm{K}, k}-n_{k}$ relation for the LSHS is similar to that of the IHS.

To study the correlation between the $D_{\mathrm{K}, k}-n_{k}$ relation of the LSHS and IHS, the $D_{\mathrm{K}, k^{-}} n_{k}$ relations of the LSHS and IHS with the same normalized effective amplitude and reinforcement conditions are plotted together. The $D_{\mathrm{E} k}-n_{k}$ relations of specimens R4 to R6, R7 to R9, and R10 to R12, according to the principle of the same normalized effective amplitude, are shown in Figure 10. It is not difficult to find that the $D_{\mathrm{K}, k}-n_{k}$ relation for the LSHS can be obtained by translating the $D_{\mathrm{K}, k}-n_{k}$ relation of the IHS to the right.

Based on the correlation of the $D_{\mathrm{K}, k}-n_{k}$ relation for the LSHS and IHS, the translation hypothesis of the $D_{\mathrm{K}, k}-n_{k}$ relation for the LSHS is proposed. The expression formula of the translation model is as follows:

$$
D_{\mathrm{K}, k}=\alpha\left(1-e^{-\beta\left(n_{k}-x_{t}\right)}\right) \text {. }
$$

Here, $x_{\mathrm{t}}$ is the translation value, Figure 11 shows the translation model of the LSHS, and $n_{c}$ is the normalized cumulative energy dissipation at the first half-cycle of the LSHS.

According to equation (7), the $D_{\mathrm{K}, k}-n_{k}$ relations for the LSHS are fitted by a nonlinear regression analysis procedure, and the values of $x_{\mathrm{t}}$ are obtained. Figure 12 shows the relationship between $x_{\mathrm{t}}$ and $n_{c}$, which shows a linear growth relationship:

$$
x_{t}=0.65 n_{c}-3.2 \text {. }
$$

Substituting equation (8) into equation (7), the estimation method of $D_{\mathrm{K}, k}$ for the LSHS is obtained. Therefore, the estimation method of $D_{\mathrm{K}, k}$ under the SV displacement patterns is as follows:

$$
D_{\mathrm{K}, k}= \begin{cases}\alpha\left(1-e^{-\beta n_{k}}\right), & \text { for IHS, } \\ \alpha\left(1-e^{-\beta\left(n_{k}-0.65 n_{c}+3.2\right)}\right), & \text { for LSHS, } \\ D_{\mathrm{K}, \mathrm{I}-1}, & \text { for SSHS. }\end{cases}
$$

Here, $D_{\mathrm{K}, \mathrm{I}-1}$ represents the estimation method of $D_{\mathrm{K}, k}$ for the SSHS, and the estimation method of the SSHS is the same as that of the previous CC stage.

3.2. The Stiffness Degradation Index under the RV Displacement Patterns. For the estimation method of the stiffness degradation index under the RV displacement patterns, the normalized effective amplitude $\mu_{k}$ needs to be transformed into a quasi-stable normalized effective amplitude according to equation (10). Then, the stiffness degradation index must 


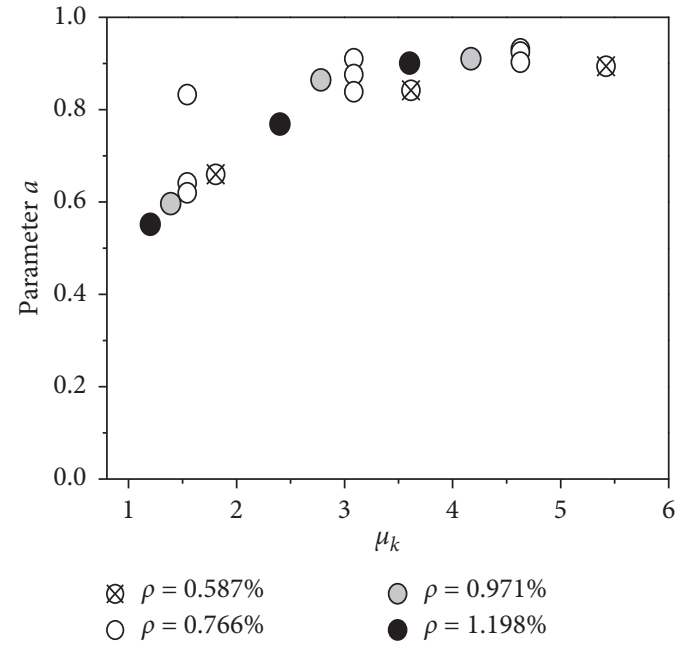

(a)

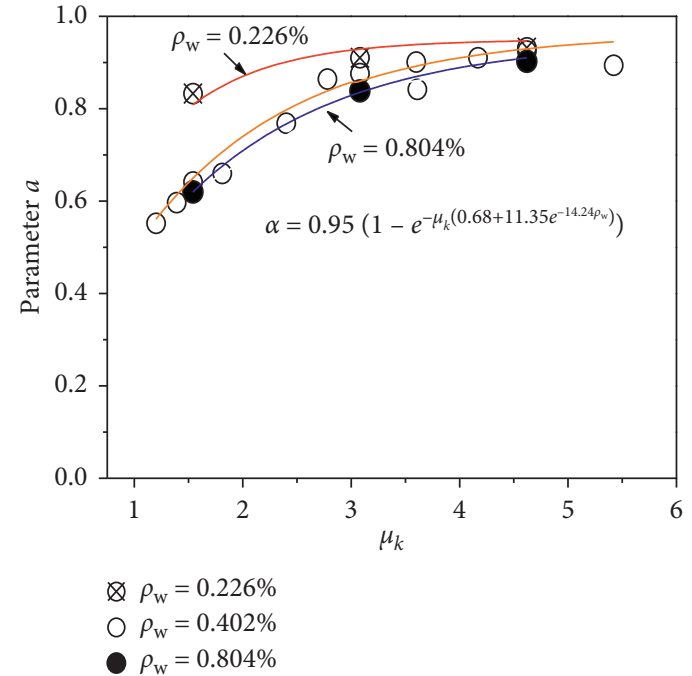

(b)

FIGURE 8: Relationship between $\mu_{k}$ and parameter $\alpha$. (a) Different symbols represent the difference in $\rho$. (b) Different symbols represent the difference in $\rho_{\mathrm{w}}$.

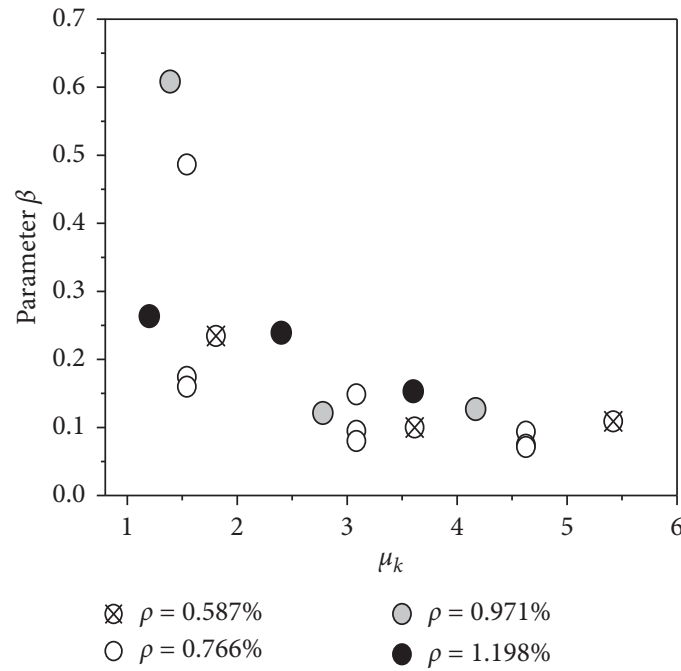

(a)

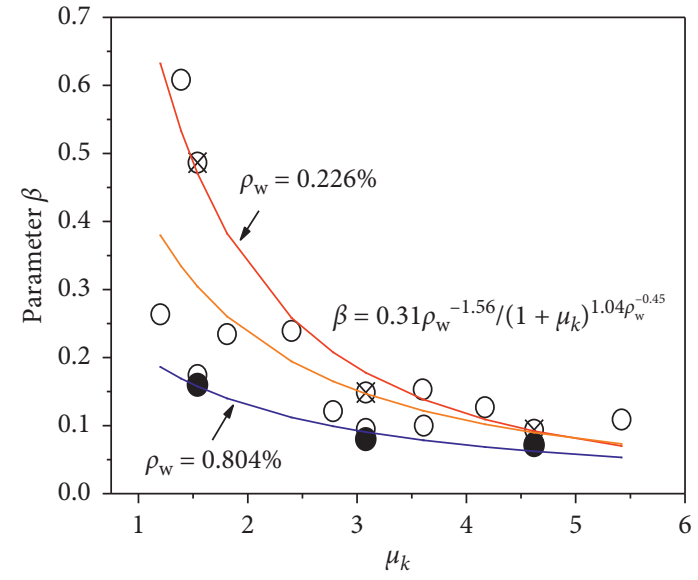

$\otimes \rho_{\mathrm{w}}=0.226 \%$

○ $\rho_{\mathrm{w}}=0.402 \%$

- $\rho_{\mathrm{w}}=0.804 \%$

(b)

FIGURE 9: Relationship between $\mu_{k}$ and parameter $\beta$. (a) Different symbols represent the difference in $\rho$. (b) Different symbols represent the difference in $\rho_{\mathrm{w}}$.

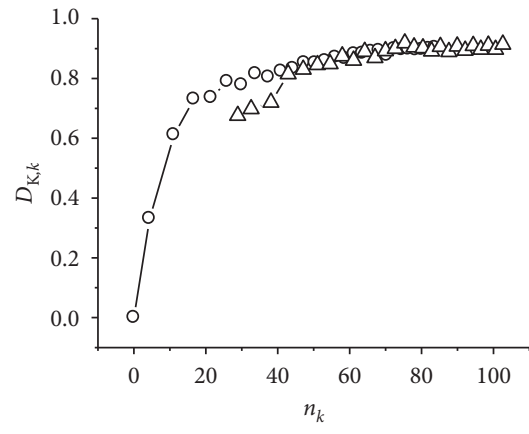

$\multimap$ 3.08-IHS of R5

$\neg$ 3.08-LSHS of R4

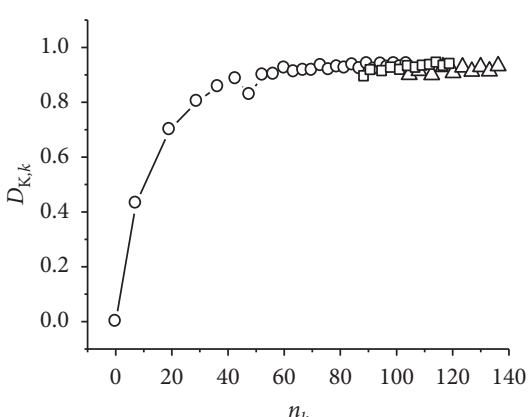

-

$\neg-4.62$-LSHS of R4

$\longrightarrow$ 4.62-LSHS of R5

(b)

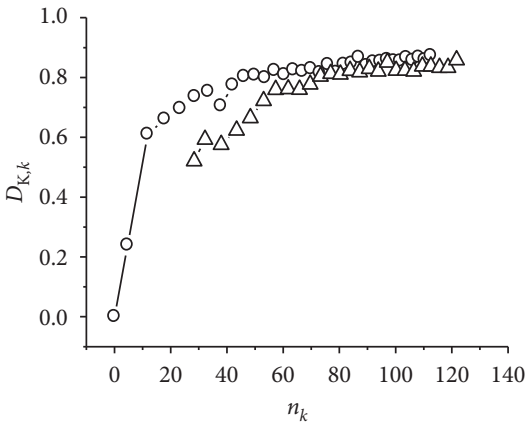

$\multimap$ 3.08-IHS of R8

$\triangle \quad$ 3.08-LSHS of R7 


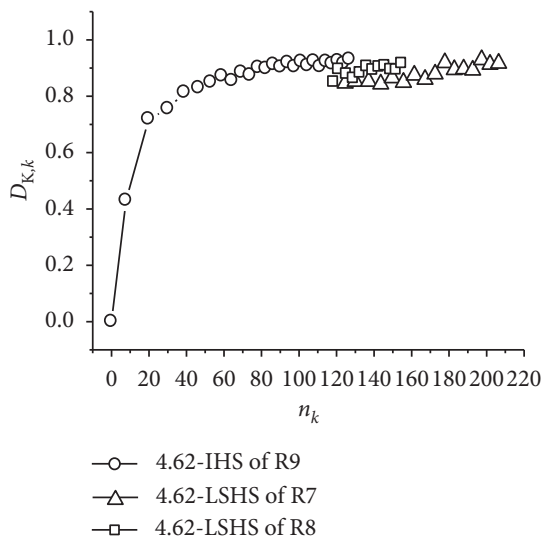

(d)

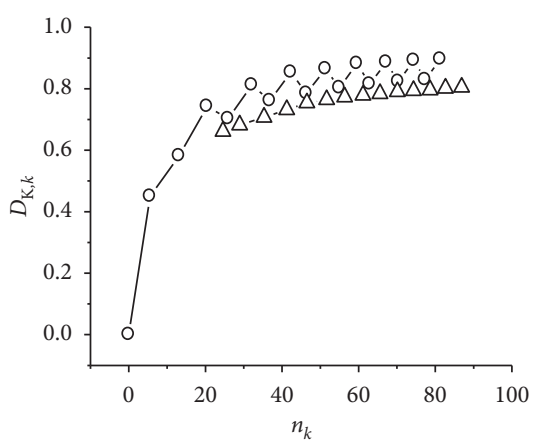

$$
\text { -0 3.61-IHS of R11 }
$$$$
\triangle \text { 3.61-LSHS of R10 }
$$

(e)

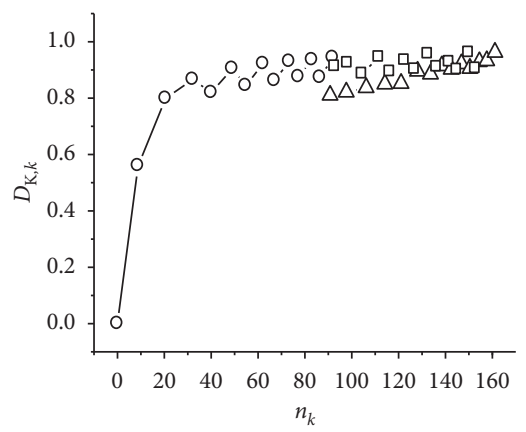

$\rightarrow$ 5.42-IHS of R12

$\triangle \quad$ 5.42-LSHS of R10

$\rightarrow$ 5.42-LSHS of R11

(f)

FIGURE 10: $\mathrm{D}_{\mathrm{E} k^{-}} n_{k}$ relations for specimens $\mathrm{R} 4$ to R6, R7 to R9, and R10 to R12 according to the principle of the same normalized effective amplitude.

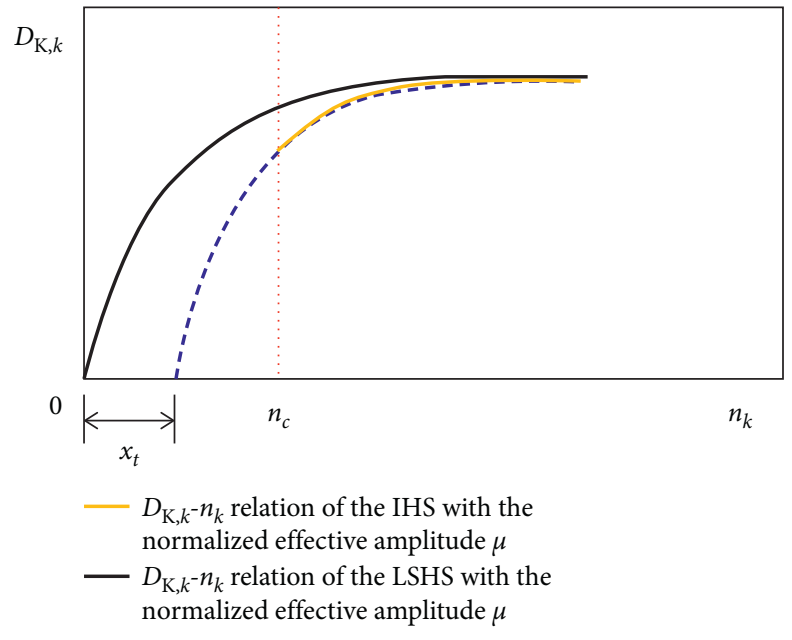

FIgURE 11: The translation model of LSHS.

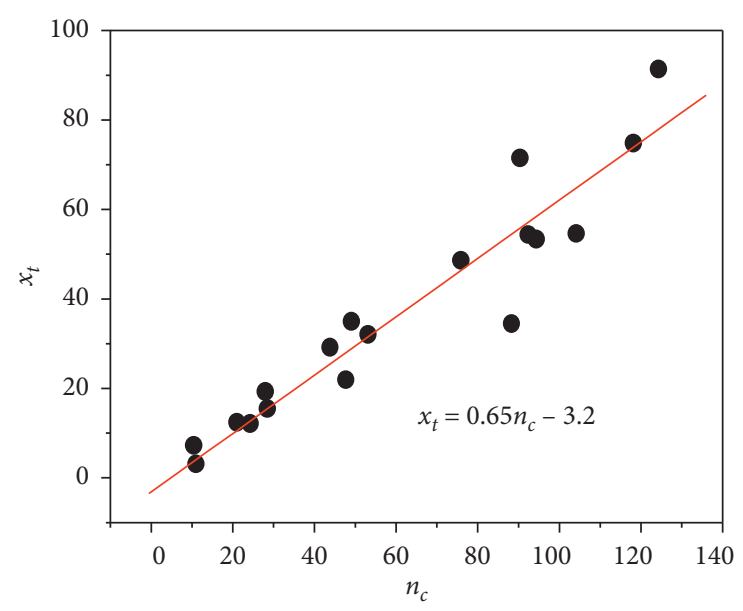

FIGURE 12: Relationship between $x_{\mathrm{t}}$ and $n_{c}$.

be calculated according to the estimation method of $D_{\mathrm{K}, k}$ for the SV displacement patterns. The meaning of equation (10) is that the normalized effective amplitude $\mu_{k}$ of the similar half-cycles is replaced by the average value. To identify the continuous half-cycles with similar normalized effective amplitudes, equations (11) and (12) are applied. Figure 13 


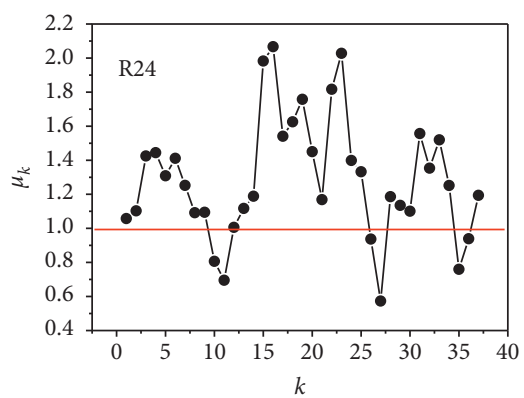

(a)

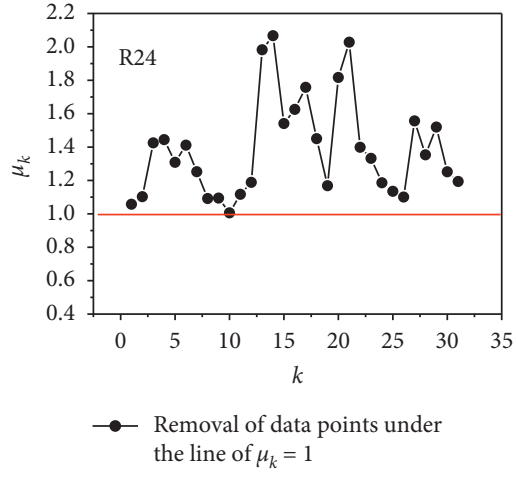

(b)

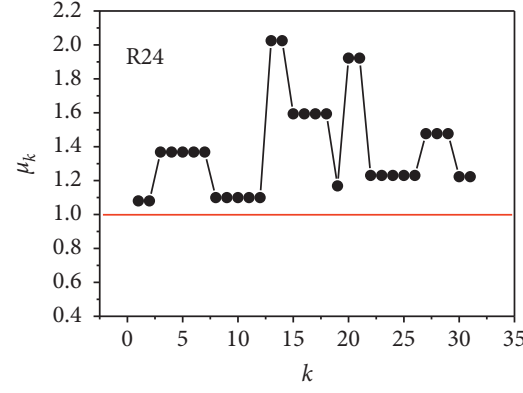

Averaging of the similar $\mu_{k}$ values

(c)

Figure 13: The process of the quasi-stable normalized effective amplitude for specimen R24. (a). The value of $\mu_{k}$ of specimen R24. (b) Removal of the data points under the line of $\mu_{k}=1$. (c) Averaging of the similar values of $\mu_{k}$.

shows the process of the quasi-stable normalized effective amplitude for specimen R24. See companion paper [17] for the detailed calculation process:

$$
\begin{aligned}
& \mu_{k}=\frac{1}{b-a+2} \sum_{j=a-1}^{b} \mu_{j}, \quad(k=a-1, b), \\
&\left|u_{j}-u_{j-1}\right|<0.15 u_{\max }, \quad(j=a, b), \\
& \sum_{j=a}^{b}\left(u_{j}-u_{j-1}\right)<0.15 u_{\max } .
\end{aligned}
$$

where $u_{\max }$ is the maximum normalized effective amplitude.

For the estimation method of $n_{k}$, the energy dissipation of the $k$-th half-cycle $E_{\mathrm{H}, k}$ needs to be calculated first according to the companion paper [17], and then $n_{k}$ is estimated by equation (3). The companion paper [17] proposed computing the energy dissipation of the $k$-th halfcycle $E_{\mathrm{H}, k}$ as follows:

$$
E_{\mathrm{H}, k}=f\left(\rho_{\mathrm{w}}, V_{\mathrm{y}}, u_{\mathrm{y}}, \mu_{k}\right) .
$$

Figure 14 shows the prediction procedure of $D_{\mathrm{K}, k}$. The previous step of the calculation of $D_{\mathrm{K}, k}$ requires the calculation of $n_{k}$ by equation (3). In the calculation of equation (9), it is necessary to judge the subsequent half-cycle sequence as the LSHS or SSHS according to the loading displacement history and then select the corresponding estimation method. In summary, the value of $D_{\mathrm{K}, k}$ is dependent on both the cumulative energy dissipation (cumulative damage term) and displacement history (deformation damage term).

The test data of 7 specimens (specimens R25 to R31 in Table 3) with the following conditions were selected from the Pacific Earthquake Engineering Research Center (PEER) database: (a) the failure type is flexural failure; (b) the axial load is zero; and (c) the section is rectangular. The yield loads and the yield displacements were calculated from the skeletal curves of the hysteresis curves according to the equal energy criterion. The properties of the 7 specimens in the PEER database are shown in Table 3.

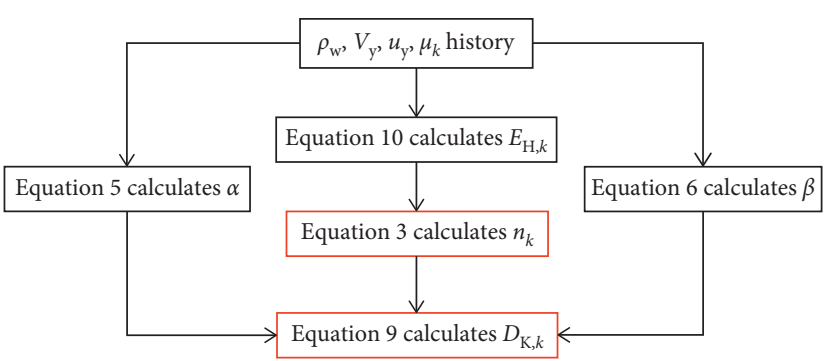

FIgURe 14: Prediction procedure of $D_{\mathrm{K}, k}$.

Table 3: The properties of 7 specimens in the PEER database.

\begin{tabular}{lcccccc}
\hline No. & $\begin{array}{c}\text { Data } \\
\text { sources }\end{array}$ & $V_{\mathrm{y}}(\mathrm{kN})$ & $\begin{array}{c}u_{\mathrm{y}} \\
(\mathrm{mm})\end{array}$ & $B \times h(\mathrm{~mm})$ & $\rho(\%)$ & $\begin{array}{c}\rho_{\mathrm{w}} \\
(\%)\end{array}$ \\
\hline R25 & ORC1 [18] & 251.71 & 37.92 & $305 \times 508$ & 1.265 & 1.372 \\
$\mathrm{R} 26$ & C5-00N [19] & 57.83 & 13.22 & $203 \times 203$ & 0.965 & 0.9 \\
$\mathrm{R} 27$ & C5-00S [19] & & & & & \\
$\mathrm{R} 28$ & U1 [20] & 263.75 & 24.72 & $350 \times 350$ & 1.605 & 0.3 \\
$\mathrm{R} 29$ & A1 [21] & 45.37 & 12.44 & & & 0.623 \\
$\mathrm{R} 30$ & B1 [21] & 36.39 & 9.48 & $152.4 \times 152.4$ & 1.225 & 0.705 \\
$\mathrm{R} 31$ & C1 [21] & 38.74 & 14.00 & & & \\
\hline
\end{tabular}

To understand the accuracy of the estimation method, Figure 15 shows the estimated values and experimental values of each half-cycle for 31 specimens, where the abscissa is the experimental value and the ordinate is the estimated value. The hollow point is $D_{\mathrm{K}, k}$ for specimens $\mathrm{R} 1$ to R24, and the solid point is $D_{\mathrm{K}, k}$ for specimens R25 to R31 in the PEER database. The results show that the proposed method provides promising prediction reliability and accuracy.

\section{Performance Classification Levels of the Stiffness Degeneration Index}

The damage development process of specimens R1 to R24 was not recorded in detail during the test. Therefore, specimens R1 to R24 cannot be used to study the performance classification levels of the stiffness degradation index. The damage development process was recorded for 


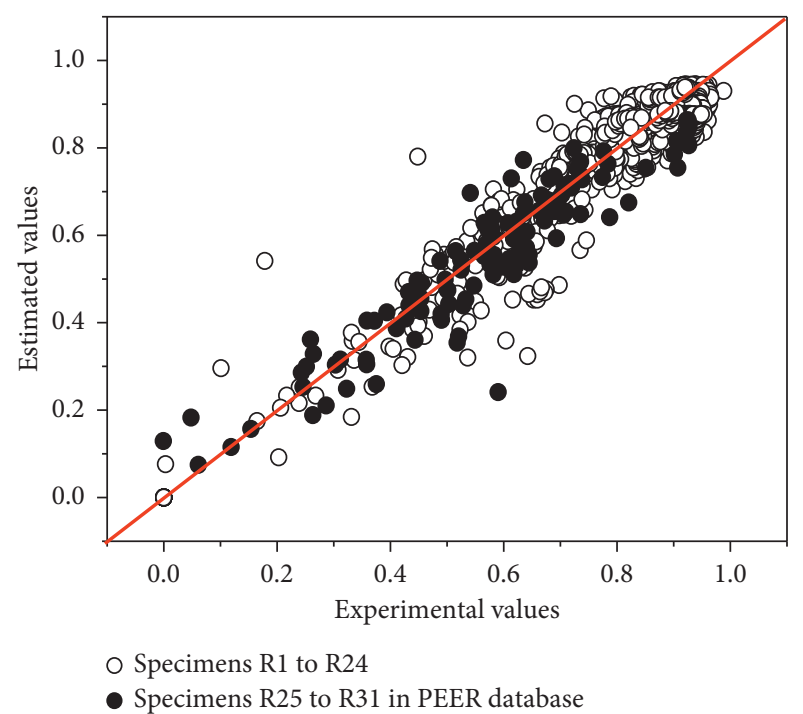

FIgURE 15: Estimated values and experimental values of $D_{\mathrm{K}, k}$ for each half-cycle for 31 specimens.

specimens $S 1$ to $S 9$ from reference [22], and the damage stages faithfully corresponded to the number of half-cycles. The damage stages of specimens S1 to S9 were divided as concrete cracking, slight spalling of the concrete, severe spalling of the concrete, and buckling of the longitudinal reinforcement. The four performance levels corresponding to the four damage stages are mild damage, moderate damage, severe damage, and destruction. Therefore, specimens S1 to S9 from the reference [22] were used to discuss the performance classification levels of the stiffness degeneration index. The properties and the number of halfcycles corresponding to the damage of specimens S1 to S9 are shown in Table 4.

The dimensions of specimens S1 to S9 are the same as those of specimens R1 to R24. Specimens S1 to S9 were divided into three groups according to the reinforcement type. There were three specimens in each group with the same reinforcement type. Group 1 and group 2 have the same transverse reinforcement ratio at the plastic hinge region but different longitudinal reinforcement ratios in the test section. Group 2 and group 3 have the same longitudinal reinforcement ratio in the test section but different transverse reinforcement ratios. Four RV displacement patterns were imposed on specimens $S 1$ to $S 9: B 1, B 1-X, B 1-D$, and B2. Each displacement pattern contained the main part (black solid line) and the additional part (blue solid line) in Figure 16. Figure 17 shows hysteresis of the loops for specimens S1 to S9, and the different symbols are used to represent the different damage stages.

Figure 18 shows the $D_{\mathrm{K}, k^{-}}-k$ relations for specimens $\mathrm{S} 1$ to S9. It can be seen from Figure 18 that the $D_{\mathrm{K}, k^{-}}-k$ relations exhibit a zigzag pattern due to the asymmetry of the stiffness degradation of the positive and negative half-cycles, but it does not affect the tendency of $D_{\mathrm{K}, k}$ to increase monotonically from 0 to 1 . Comparing specimens S1 and S2 with specimens S7 and S8 in Figure 18(a), it can be found that, under the same displacement pattern, the increase in the reinforcement ratio can significantly slow down the development of $D_{\mathrm{K}, k}$, and similar phenomena can be observed in Figure 18(c). Comparing specimens S4, S5, and S6 in Figure 18(b), it can be seen that, under the same reinforcement conditions, the difference in the displacement pattern has a significant impact on the development of $D_{\mathrm{K}, k}$. For the three specimens, when the B1-X displacement pattern (the displacement amplitude of the main part increases from small to large) is adopted, the development of $D_{\mathrm{K}, k}$ is the slowest. When the B1-D displacement pattern (the displacement amplitude of the main part increases from large to small) is adopted, the development of $D_{\mathrm{K}, k}$ is the fastest.

Figure 18 shows that, regardless of the difference between the reinforcement condition and displacement pattern, the $D_{\mathrm{K}, k}$ values for the same damage stage are similar. The cracking of the concrete is distributed in the range of $0 \sim 0.3$, the slight spalling of the concrete is distributed in the range of $0.3 \sim 0.7$, the severe spalling of the concrete is in the range of 0.7 0.9, and the buckling of the longitudinal reinforcement is distributed in the range of $0.9 \sim 0.1$. This result shows that the performance levels of the reinforced concrete members can be graded by using the value of $D_{\mathrm{K}, k}$. Table 5 shows the performance classification levels of the reinforced concrete members based on the value of $D_{\mathrm{K}, k}$.

Substituting equations (3), (5) and (6) into equation (9) gives the following:

$$
D_{\mathrm{K}, k}=g\left(\mu_{k}, \sum_{i=1}^{k-1} E_{\mathrm{H}, i}, V_{\mathrm{y}}, u_{\mathrm{y}}, \rho_{\mathrm{w}}\right) .
$$

According to equation (14), when $D_{\mathrm{K}, k}$ is defined as the damage state of the reinforced concrete member at the end of the earthquake action (performance design objective), $\mu_{k}$ and $\sum_{i=1}^{k-1} E_{\mathrm{H}, i}$ are the ductility demand and the energy demand, respectively. $V_{\mathrm{y}}$ and $u_{\mathrm{y}}$ are related to the section size, concrete strength, and reinforcement ratio. Therefore, when the ductility demand, the energy demand, and the performance design objective of reinforced concrete members are determined, the geometrical dimensions of the member, the concrete strength, and the transverse reinforcement ratio can be obtained. Therefore, this method can be used for the performance design of reinforced concrete members.

\section{Correlation between $D_{\mathrm{K}, k}$ and Different Parameters}

The correlation between $D_{\mathrm{K}, k}$ and different parameters is discussed according to equation (9). Since the estimation method of $D_{\mathrm{K}, k}$ for the SSHS can be replaced by the estimation method of the previous CC stage, equation (9) can be expressed in another form:

$$
D_{\mathrm{K}, k}=\alpha_{\max }\left(1-e^{-\beta_{\max }\left(n_{k}-x_{t, \max }\right)}\right) .
$$

The values of $\alpha_{\max }, \beta_{\max }$ and $x_{t, \max }$ are calculated from 
TABLE 4: The properties and the number of half-cycles corresponding to the damage for specimens S1 to S9 [22].

\begin{tabular}{cccccccccc}
\hline \multirow{2}{*}{ Group } & No. & $V_{\mathrm{y}}(\mathrm{kN})$ & $u_{\mathrm{y}}(\mathrm{mm})$ & $\rho_{\mathrm{w}}(\%)$ & $\rho(\%)$ & Displacement pattern & \multicolumn{2}{c}{ The number of half-cycles corresponding to damage } \\
Cracking & Spalling & Severe spalling \\
Buckling
\end{tabular}

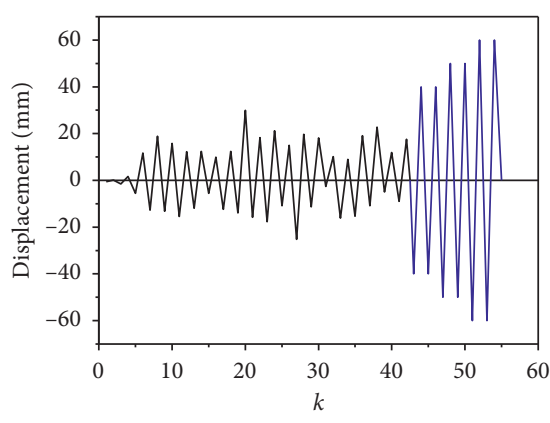

(a)

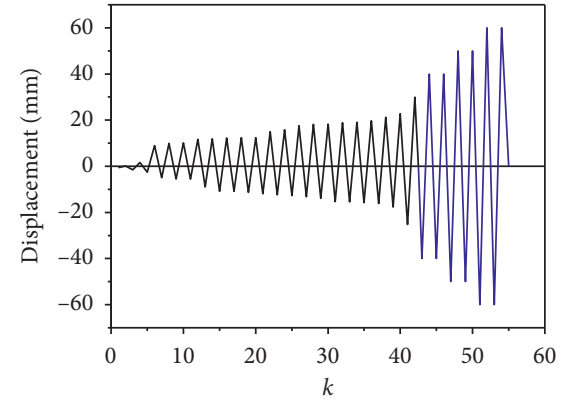

(b)

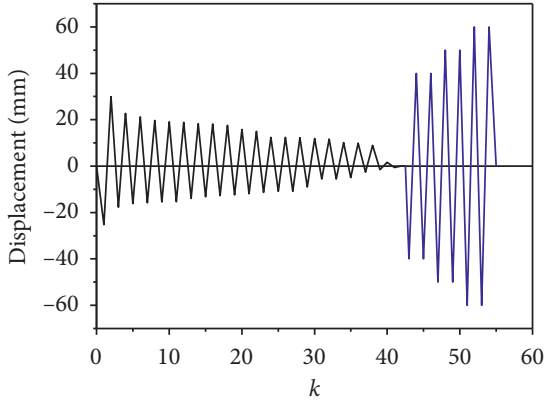

(c)

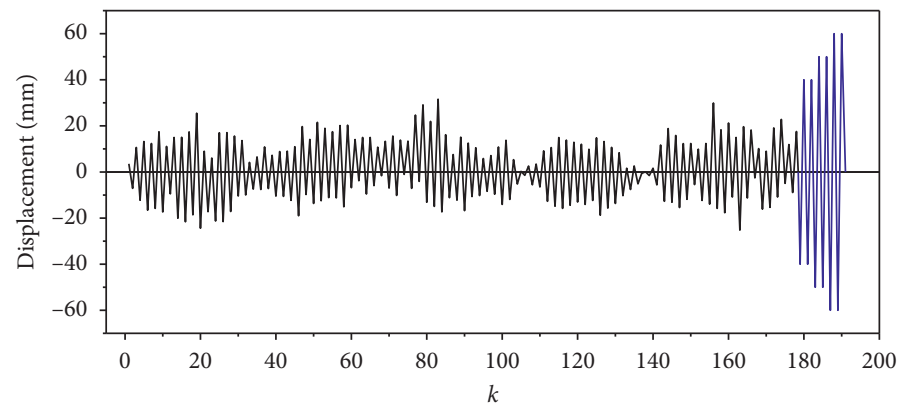

(d)

Figure 16: Four displacement patterns imposed on specimens S1 to S9: (a) B1. (b) B1-X. (c) B1-D. (d) B2.

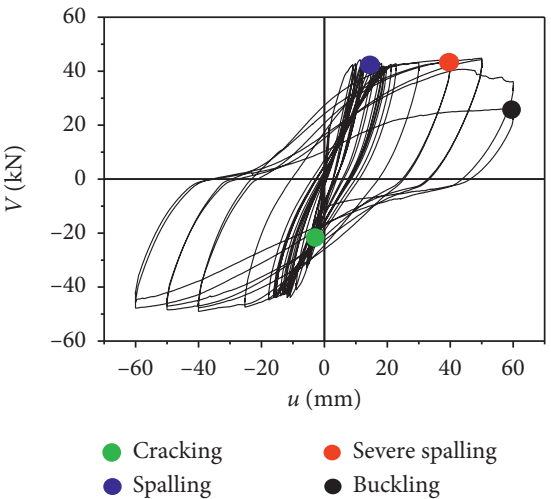

(a)

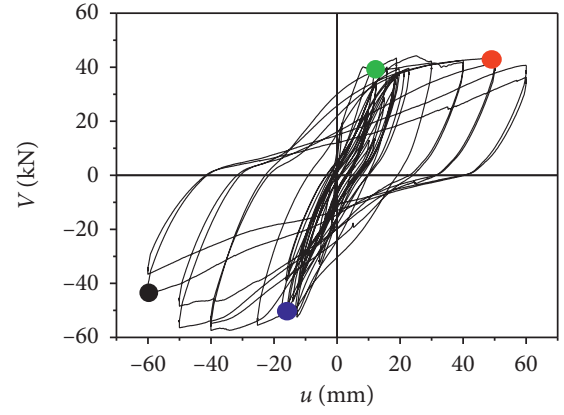

Cracking - Spalling

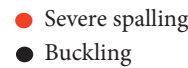

(b)

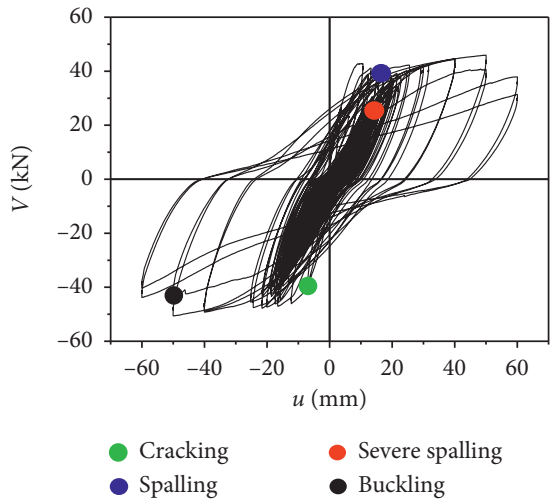

(c)

Figure 17: Continued. 


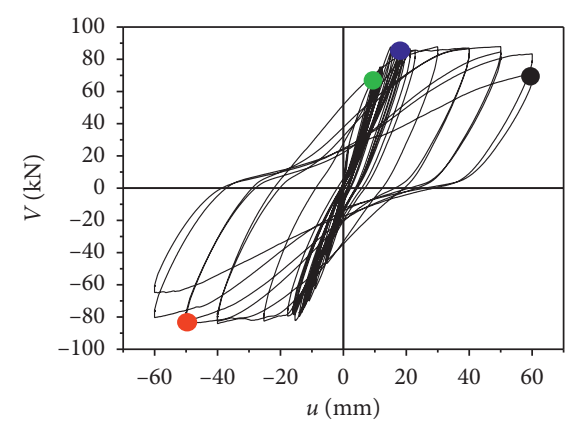

Cracking

- Spalling

- Severe spalling

- Buckling

(d)

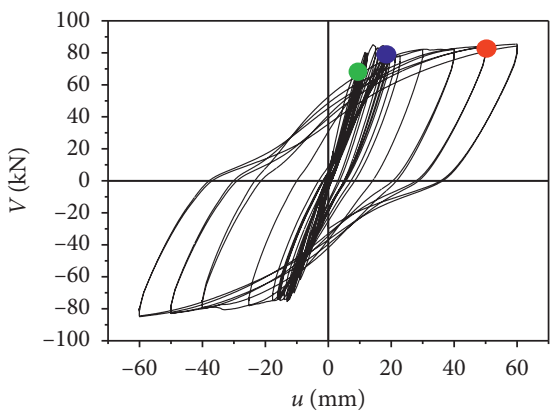

Cracking

- Spalling

- Severe spalling

(g)

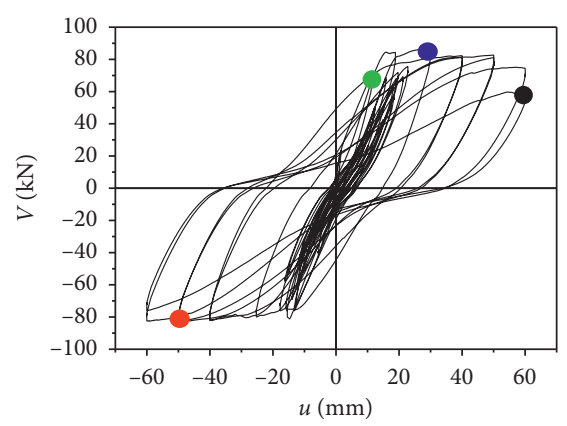

Cracking

- Spalling

- Severe spalling

- Buckling

(e)

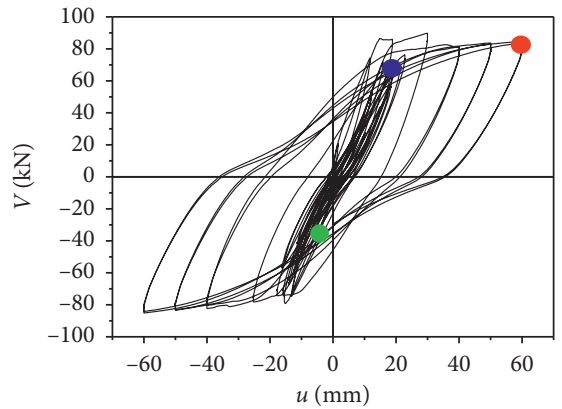

Cracking

- Spalling

- Severe spalling

(h)

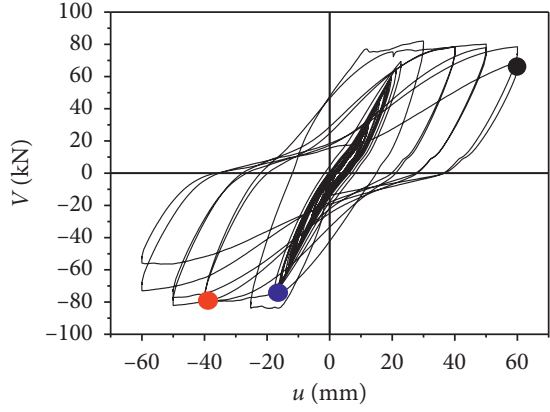

Spalling

- Severe spalling

- Buckling

(f)

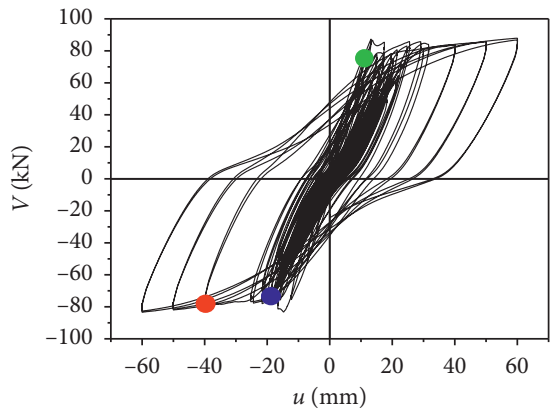

Cracking

- Spalling

- Severe spalling

Figure 17: Hysteresis loops for specimens S1 to S9: (a) S1. (b) S2. (c) S3. (d) S4. (e) S5. (f) S6. (g) S7. (h) S8. (i) S9.
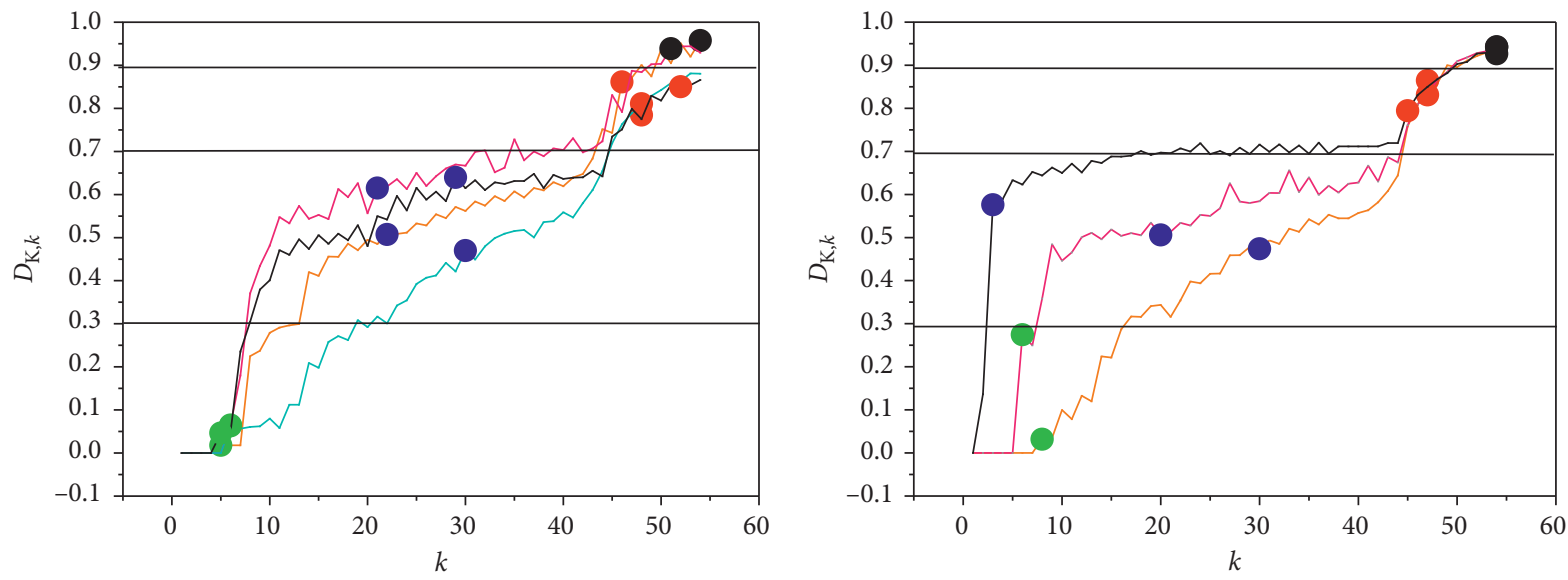

Cracking

$\because \mathrm{S} 1: \mathrm{B} 1-\mathrm{X}$

- Spalling

$\longrightarrow$ S2: B1

- Severe spalling

$\longrightarrow$ S7: B1-X

- Buckling

— S8: B1

- Cracking

- Spalling

- Severe spalling

- Buckling
- S4: B1-X

$\longrightarrow$ S5: B1

$\longrightarrow$ S6: B1-D

(b)

(a)

FIgURe 18: Continued. 


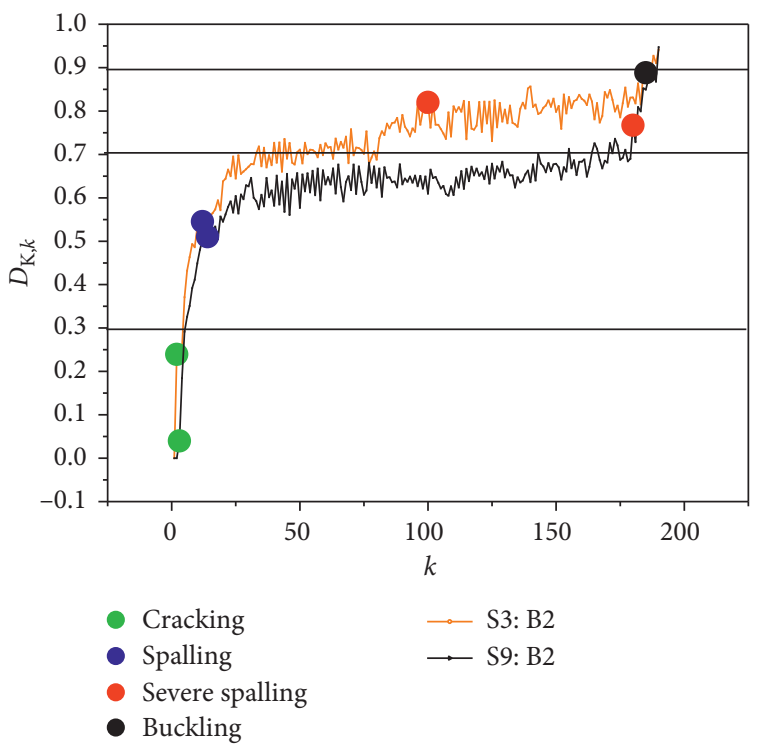

(c)

FIGURE 18: $\mathrm{D}_{\mathrm{E} k}-n_{k}$ relations for specimens $\mathrm{S} 1$ to S9: (a) S1, S2, S7 and S8. (b) S4, S5 and S6. (c) S3 and S9.

TABle 5: Performance classification levels of the reinforced concrete members based on the value of $\mathrm{D}_{\mathrm{K}, k}$.

\begin{tabular}{lcccc}
\hline No. & $D_{\mathrm{K}, k}$ & Damage stages & Performance levels & Performance status \\
\hline 1 & $D_{\mathrm{K}, k} \leq 0$ & No cracking & No damage & Intact \\
2 & $0<D_{\mathrm{K}, k} \leq 0.3$ & Cracking of the concrete & Mild damage & Repairable \\
3 & $0.3<D_{\mathrm{K}, k} \leq 0.7$ & Slight spalling of the concrete & Moderate damage & No collapse \\
4 & $0.7<D_{\mathrm{K}, k} \leq 0.9$ & Severe spalling of the concrete & Severe damage & Collapse \\
5 & $0.9<D_{\mathrm{K}, k} \leq 1$ & Buckling of the longitudinal reinforcement & Destruction & \\
\hline
\end{tabular}

$$
\begin{aligned}
\alpha_{\max } & =0.95\left(1-e^{-\mu_{k, \max }\left(0.68+11.35 e^{-14.24 \rho_{\mathrm{w}}}\right)}\right), \\
\beta_{\max } & =\frac{0.31 \rho_{\mathrm{w}}^{-1.56}}{\left(1+\mu_{k, \max }\right)^{1.04 \rho_{\mathrm{w}}^{-0.45}},} \\
x_{t, \max } & =0.65 n_{c, \text { max }}-3.2,
\end{aligned}
$$

where $\mu_{k, \max }=\max \left(\mu_{1} \ldots \mu_{k}\right), x_{t, \max }=\max \left(x_{t, 1} \ldots x_{t, k}\right)$, and when $x_{t, \text { max }}$ is less than $0, x_{t, \max }$ is equal to $0, n_{c, \max }=\max$ $\left(n_{c, 1} \ldots n_{c, k}\right)$.

Substituting equations (16) to (18) into equation (15) gives the following:

$$
D_{\mathrm{K}, k}=g\left(\rho_{\mathrm{w}}, \mu_{k, \max }, n_{k}, n_{c, \max }\right) .
$$

Figure 19 shows the correlation between $D_{\mathrm{K}, k}$ and different parameters. The $x$ coordinate axis is $\rho_{\mathrm{w}}$, which varies from $0.2 \%$ to $1 \%$. The $y$ coordinate axis is $n_{k}$, which varies from 0 to 100 , and the $z$ coordinate axis is $D_{\mathrm{K}, k}$, which varies from 0 to 1 . $\mu_{k \text { max }}$ is 3 and 1.5 , which represent the large ductility condition and the small ductility condition, respectively. $n_{c, \text { max }}$ is 10 and 90, which represent the peak displacement occurring at the front of the loading displacement history and the peak displacement occurring at the end of the loading displacement history, respectively.

As shown in Figure 19, the increase in the cumulative energy dissipation will lead to the aggravation of the stiffness damage, but the effect will slow down after the cumulative energy dissipation exceeds a threshold value. Comparing Figures 19(a) and 19(b), when the peak displacement occurs at the front of the displacement history, the stiffness damage of the reinforced concrete members will be more serious than that of the peak displacement at the end of the displacement history. The results show that the development of $D_{\mathrm{K}, k}$ is controlled by both the cumulative energy dissipation (cumulative damage term) and displacement history (deformation damage term). At the level of structural design, the increase in the transverse reinforcement ratio can reduce the damage, and the effect is more obvious under the conditions of small ductility. However, the effect will disappear after the transverse reinforcement ratio exceeds a certain threshold value. Under the same conditions, the smaller the ductility condition is, the smaller the damage of reinforced concrete members will be. Therefore, the increase in the transverse reinforcement ratio within a certain threshold range and the control of the ductility condition are stable and effective ways to control the seismic damage of reinforced concrete members. 


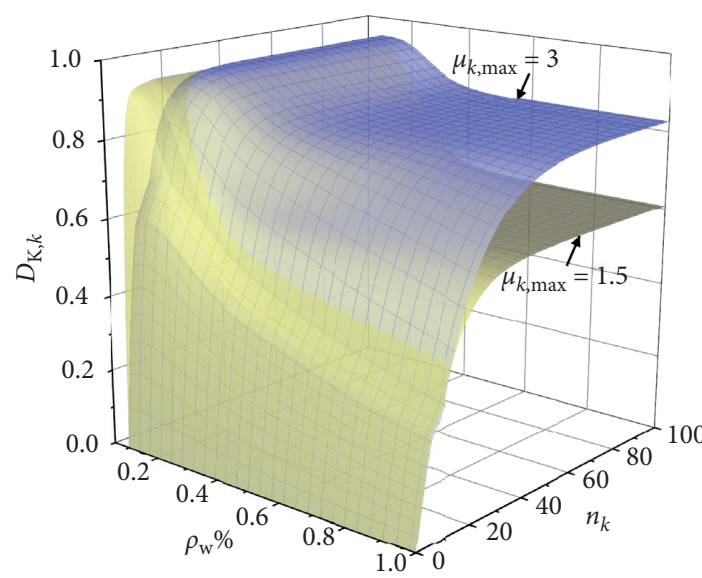

(a)

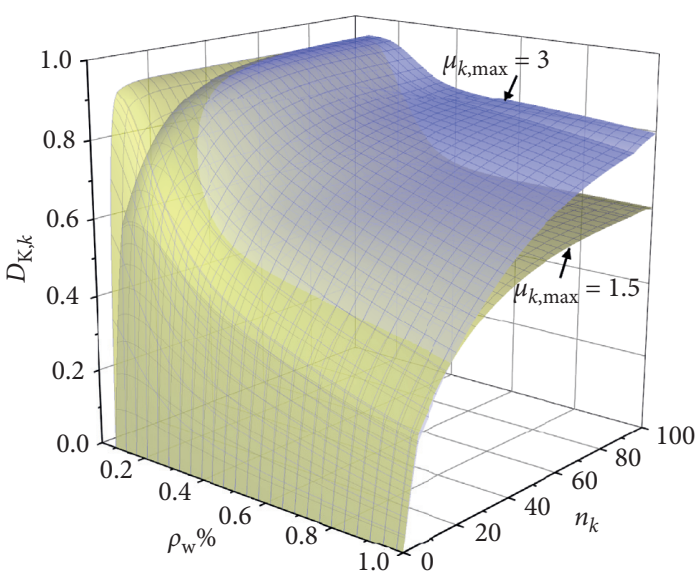

(b)

Figure 19: Correlation between $D_{\mathrm{K}, k}$ and different parameters. (a) Peak displacement occurs at the front of the displacement history. (b) Peak displacement occurs at the end of the displacement history.

\section{Conclusions}

(1) An estimation method for the stiffness degradation index was proposed, and the method provides promising prediction reliability and accuracy.

(2) The stiffness degradation index has an effective relationship with structural design parameters. Based on the stiffness degradation index, the reinforced concrete members can be divided into five performance levels, i.e., no damage $\left(D_{\mathrm{K}, k}<0\right)$, mild damage $\left(0<D_{\mathrm{K}, k} \leq 0.3\right)$, moderate damage $\left(0.3<D_{\mathrm{K}, k} \leq 0.7\right)$, severe damage $\left(0.7<D_{\mathrm{K}, k} \leq 0.9\right)$, and destruction $\left(0.9<D_{\mathrm{K}, k} \leq 1\right)$, which can provide a good reference for the seismic design of reinforced concrete members.

(3) The increase in the transverse reinforcement ratio can significantly reduce the stiffness damage, and the effect is more obvious under the conditions of small ductility. Under the same conditions, the smaller the ductility condition is, the smaller the stiffness damage of the reinforced concrete members will be. Therefore, the control of the ductility condition and the increase in the transverse reinforcement ratio are stable and effective methods for controlling the stiffness damage of reinforced concrete members.

\section{Data Availability}

The data used to support the findings of this study are available from the corresponding author upon request.

\section{Conflicts of Interest}

The authors declare that they have no conflicts of interest.

\section{Acknowledgments}

This research was supported by the Research Promotion Project of Changsha University of Science and Technology (Grant no. 2019QJCZ060), the Research and Innovation
Project of Hunan Graduate (Grant no. CX2018B537), and the Bridge Engineering Open Fund Project of Changsha University of Science and Technology (Grant no. 18KD03).

\section{References}

[1] R. D. Bertero and V. V. Bertero, "Performance-based seismic engineering: the need for a reliable conceptual comprehensive approach," Earthquake Engineering \& Structural Dynamics, vol. 31, no. 3, pp. 627-652, 2002.

[2] J. Su, Z. Li, J. Wang, and R. P. Dhakal, "Numerical simulation and damage analysis of RC bridge piers reinforced with varying yield strength steel reinforcement," Soil Dynamics and Earthquake Engineering, vol. 130, Article ID 106007, 2020.

[3] A. Ghobarah, "Performance-based design in earthquake engineering: state of development," Engineering Structures, vol. 23, no. 8, pp. 878-884, 2001.

[4] J. Su, R. P. Dhakal, and J. Junjie Wang, "Fiber-based damage analysis of reinforced concrete bridge piers," Soil Dynamics and Earthquake Engineering, vol. 96, pp. 13-34, 2017.

[5] Y. J. Park and A. H. S. Ang, "Mechanistic seismic damage model for reinforced concrete," Journal of Structural Engineering, vol. 111, no. 4, pp. 722-739, 1985.

[6] A. Moustafa, "Damage-based design earthquake loads for single-degree-of-freedom inelastic structures," Journal of Structural Engineering ASCE, vol. 137, no. 4, pp. 456-467, 2011.

[7] K. Kostinakis, K. Morfidis, and H. Xenidis, "Damage response of multistorey $\mathrm{r} / \mathrm{c}$ buildings with different structural systems subjected to seismic motion of arbitrary orientation," Earthquake Engineering \& Structural Dynamics, vol. 44, no. 12, pp. 1919-1937, 2015.

[8] Y. Feng, M. J. Kowalsky, and J. M. Nau, "Effect of seismic load history on deformation limit states for longitudinal bar buckling in RC circular columns," Journal of Structural Engineering ASCE, vol. 141, no. 8, Article ID 04014187, 2015.

[9] D. V. Syntzirma, S. J. Pantazopoulou, and M. Aschheim, "Load-history effects on deformation capacity of flexural members limited by bar buckling," Journal of Structural Engineering, vol. 136, no. 1, pp. 1-11, 2010.

[10] A. Benavent-Climent, D. Escolano-Margarit, and L. Morillas, "Shake-table tests of a reinforced concrete frame designed following modern codes: seismic performance and damage 
evaluation," Earthquake Engineering \& Structural Dynamics, vol. 43, no. 6, pp. 791-810, 2014.

[11] R. Rajabi, M. Barghi, and R. Rajabi, "Investigation of ParkAng damage index model for flexural behavior of reinforced concrete columns," The Structural Design of Tall and Special Buildings, vol. 22, no. 17, pp. 1350-1358, 2013.

[12] J. Carrillo, "Damage index based on stiffness degradation of low-rise RC walls," Earthquake Engineering \& Structural Dynamics, vol. 44, no. 6, pp. 831-848, 2015.

[13] T. N. Do and F. C. Filippou, "A damage model for structures with degrading response," Earthquake Engineering \& Structural Dynamics, vol. 47, no. 2, pp. 311-332, 2018.

[14] P.-H. Wang, Y.-C. Ou, and K.-C. Chang, "A new smooth hysteretic model for ductile flexural-dominated reinforced concrete bridge columns," Earthquake Engineering \& Structural Dynamics, vol. 46, no. 14, pp. 2237-2259, 2017.

[15] A. Massumi and E. Moshtagh, "A new damage index for RC buildings based on variations of nonlinear fundamental period," The Structural Design of Tall and Special Buildings, vol. 22, no. 1, pp. 50-61, 2013.

[16] R. Scotta, L. Tesser, R. Vitaliani, and A. Saetta, "Global damage indexes for the seismic performance assessment of RC structures," Earthquake Engineering and Structural Dynamics, vol. 38, no. 8, pp. 1027-1049, 2009.

[17] Z. Liu, Y. Wang, Z. Cao, Y. Chen, and Y. Hu, "Seismic energy dissipation under variable amplitude loading for rectangular RC members in flexure," Earthquake Engineering \& Structural Dynamics, vol. 47, no. 4, pp. 831-853, 2018.

[18] R. S. Aboutaha and R. I. Machado, "Seismic resistance of steeltubed high-strength reinforced-concrete columns," Journal of Structural Engineering, vol. 125, no. 5, pp. 485-494, 1999.

[19] A. B. Matamoros, Study of Drift Limits for High-Strength Concrete Columns, Department of Civil Engineering, University of Illinois at Urbana-Champaign, Urbana, IL, USA, 1999.

[20] M. Saatcioglu and G. Ozcebe, "Response of reinforced concrete columns to simulated seismic loading," ACI Structural Journal, vol. 86, no. 1, pp. 3-12, 1989.

[21] J. H. Thomson and J. W. Wallace, "Lateral load behavior of reinforced concrete columns constructed using high-strength materials," ACI Structural Journal, vol. 91, no. 5, pp. 605-615, 1994.

[22] Y. K. Wang, Z. F. Liu, W. J. Yang, Y. Hu, and Y. Chen, "Damage index of reinforced concrete members based on the energy dissipation capability degradation," The Structural Design of Tall and Special Buildings, vol. 29, no. 2, p. e1695, 2019. 